\title{
Analysis and theory of gas transport in microporous sol-gel derived ceramic membranes
}

\author{
R.S.A. de Lange, K. Keizer *, A.J. Burggraaf \\ University of Twente, Faculty of Chemical Technology, Laboratory for Inorganic Chemistry, Materials Science and Catalysis, P.O. Box 217, \\ 7500 AE Enschede, The Netherlands
}

Received 15 August 1994; revised 2 January 1995; accepted 6 January 1995

\begin{abstract}
Sol-gel modification of mesoporous alumina membranes is a very successful technique to improve gas separation performance. Due to the formed microporous top layer, the membranes show activated transport and molecular sieve-like separation factors. This paper concentrates on the mechanism of activated transport (also often referred to as micropore diffusion or molecular sieving). Based on a theoretical analysis, results from permeation and separation experiments with $\mathrm{H}_{2}, \mathrm{CO}_{2}, \mathrm{O}_{2}, \mathrm{~N}_{2}, \mathrm{CH}_{4}$ and iso- $\mathrm{C}_{4} \mathrm{H}_{10}$ on microporous sol-gel modified supported ceramic membranes are integrated with sorption data.

Gas permeation through these membranes is activated, and for defect-free membranes the activation energies are in the order of 13-15 kJ.mol ${ }^{-1}$ and 5-6 kJ.mol ${ }^{-1}$ for $\mathrm{H}_{2}$ and $\mathrm{CO}_{2}$ respectively. Representative permeation values are in the order of $6 \times 10^{-7}$ mol.m $\mathrm{m}^{-2} \cdot \mathrm{s}^{-1} \cdot \mathrm{Pa}^{-1}$ and $20 \times 10^{-7} \mathrm{~mol} \cdot \mathrm{m}^{-2} \cdot \mathrm{s}^{-1} \cdot \mathrm{Pa}^{-1}$ for $\mathrm{H}_{2}$ at $25^{\circ} \mathrm{C}$ and $200^{\circ} \mathrm{C}$, respectively. Separation factors for $\mathrm{H}_{2} / \mathrm{CH}_{4}$ and $\mathrm{H}_{2}$ /iso-butane are in the order of 30 and 200 at $200^{\circ} \mathrm{C}$, respectively, for high quality membranes.

Processes which strongly determine gas transport through microporous materials are sorption and micropore diffusion. Consequently, the activation energy for permeation is an apparent one, consisting of a contribution from the isosteric heat of adsorption and the activation energy for micropore diffusion. An extensive model is given to analyse these contributions.

For the experimental conditions studied, the analysis of the gas transport mechanism shows that interface processes are not rate determining. The calculated activation energies for micropore diffusion are $21 \mathrm{~kJ} \cdot \mathrm{mol}^{-1}$ and $32 \mathrm{~kJ} \cdot \mathrm{mol}^{-1}$ for $\mathrm{H}_{2}$ and $\mathrm{CO}_{2}$, respectively. Comparison with zeolite diffusion data shows that these activation energies are higher than for zeolite $4 \mathrm{~A}\left(d_{\text {pore }}=4\right.$ $\AA)$, indicating that the average pore size of the sol-gel derived membranes is probably smaller.
\end{abstract}

Keywords: Ceramic membranes; Microporous; Gas transport mechanism

\section{General introduction}

Separation technology plays an important role in many manufacturing processes. In the petrochemical industry, for example, separation technology can require $40-70 \%$ in the capital costs of new plants [1] Within separation technology, the use of membrane processes for different kinds of separation processes is

\footnotetext{
* Corresponding author.
}

a strongly expanding field, which showed a major breakthrough in the 1970's due to the development of new polymeric membrane materials. Before the beginning of the 1980's, the use of inorganic membranes was limited to enrichment of $U^{235}$ [2]. The development of industrial inorganic ultrafiltration (UF, pore diameters in the order of 4-200 nm, separation of macromolecules or colloidal particles) and microfiltration (MF, pore diameters in the order of 4-200 nm, separation of par- 
ticles in the order of $100 \mathrm{~nm}$ or above) membranes started in the period 1980-1985.

In the last decade, an important direction in research and development in the inorganic membrane field has been to decrease the pore size of the porous membranes. Microporous ( $r_{\text {pore }}<1 \mathrm{~nm}[3]$ ) inorganic membranes are attracting much attention in the field of separation technology for applications in gas separation processes [4-7]. This is mainly due to their high, molecular sieve-like, selectivities, and high stability at enhanced temperatures and in chemically aggressive atmospheres (compared to polymeric membranes).

Furthermore, the application of inorganic membranes in so-called membrane reactors, using catalytically active or passive membranes, has proven to be very promising and an increasing research effort in this field is observed in the past few years [8-11]. Recent model studies of Zaspalis and Keizer et al. [12,13] show that the incorporation of microporous membranes in these membrane reactor systems can be very advantageous. If conditions are chosen correctly, high selectivities, e.g. for $\mathrm{H}_{2}$ in dehydrogenation reactions, allow the achievement of high conversions, by factors $7-8$ times higher than equilibrium conversion at that temperature, while the high permeabilities allow operation at industrially attractive conditions.

\subsection{Microporous inorganic membrane types}

Based on synthesis route and material, one can roughly distinguish 5 main types of inorganic microporous ${ }^{1}$ membranes. These are: (i) sol-gel derived ceramic membranes, (ii) CVD modified (glass or ceramic) membranes, (iii) leached hollow glass fibers, (iv) carbon molecular sieve membranes and (v) zeolite membranes.

A very successful process for the preparation of microporous membranes is sol-gel modification of mesoporous ( $\left.1 \mathrm{~nm}<r_{\text {pore }}<25 \mathrm{~nm}[3]\right)$ membranes with polymeric silica sols [14-21]. Gas permeation rates through these membranes are relatively high, mainly due to the very thin top-layers, in the order of $50-100 \mathrm{~nm}$. Gas separation factors are typically in the

\footnotetext{
${ }^{1}$ Note: Dense inorganic membranes, based on palladium and its alloys or solid oxide electrolytes (zirconia), will not be considered in this paper.
}

order of 100-200 $\left(\mathrm{H}_{2} /\right.$ propene, $\mathrm{H}_{2} / \mathrm{CH}_{4}$ $\left.[14,16,17,20,21], \mathrm{He} / \mathrm{N}_{2}[15]\right)$.

CVD modification [22-25] of mesoporous glass or ceramic membranes, can result in very high separation factors in the order of $1000\left(\mathrm{He} / \mathrm{N}_{2}[24]\right)$ to $>3000$ $\left(\mathrm{H}_{2} / \mathrm{N}_{2}[23]\right)$. However, the permeation rates, are generally a factor 100 lower than for sol-gel modified derived microporous membranes.

Microporous hollow glass fibers can be prepared by leaching of the borosilicate component of hollow glass fibers [26]. The gas permeation rates are comparable with sol-gel derived systems. Controlled carbonization of organics leads to the formation of molecular sieve carbons, which are also used on a large scale in pressure swing adsorption processes [27].

The development of zeolite membranes is a strongly increasing part of present membrane research [28-31]. Advantages of these systems are the very narrow pore size distribution (in fact there is only a single crystallographic pore size) and the generally higher chemical stability. A review of this field is given by Burggraaf et al. [6].

\subsection{Scope of this paper}

One of the most characteristic properties of microporous membranes, which results in very high separation factors, is activated gas transport. It has been found phenomenologically that the flux $J$ (mol.m $\mathrm{m}^{-2} \cdot \mathrm{s}^{-1}$ ) through microporous materials increases as function of temperature according to:

$J \propto J_{0} \exp \left(\frac{-E_{\text {act. }}}{R T}\right)$

where $E_{\text {act. }}\left(\mathrm{kJ} \cdot \mathrm{mol}^{-1}\right)$ is an apparent activation energy. Depending on micropore size and gas molecule size, activation energies ranging from around 2 to 40 $\mathrm{kJ} . \mathrm{mol}^{-1}$ have been reported [14-17,32-34].

In mesoporous materials, as for example $\gamma$-alumina membranes, the gas transport mechanisms are: (i) Knudsen diffusion, (ii) laminar (or Poiseuille) flow and (iii) surface diffusion. However, according to these mechanisms, transport rates decrease as function of temperature as shown by Eqs. 2-4 [35]:

(i) Knudsen diffusion

$$
F_{\mathrm{Kn}, 0}=\frac{2 . \epsilon_{p} \cdot \mu_{\mathrm{Kn}} \cdot \bar{v} \cdot \bar{r}}{3 R T L} \text { with } \bar{v}=\sqrt{\frac{8 R T}{\pi M}}
$$


Where $F_{\mathrm{Kn}, 0}$ is the Knudsen permeation $\left(\mathrm{mol} \cdot \mathrm{m}^{-2} \cdot \mathrm{s}^{-1} \cdot \mathrm{Pa}^{-1}\right), \epsilon_{\mathrm{p}}$ is the porosity $(-), \mu_{\mathrm{Kn}}$ is a shape factor $(-)$ equal to $1 / \tau$, where $\tau$ is the tortuosity, $R$ is the gas constant $\left(\mathrm{J} \cdot \mathrm{mol}^{-1} \cdot \mathrm{K}^{-1}\right), T$ is the absolute temperature (K), $\vec{r}$ is the modal pore radius $(\mathrm{m}), \bar{v}$ is the average molecular velocity $\left(\mathrm{m} . \mathrm{s}^{-1}\right), L$ is the layer thickness (m) and $M$ is the molecular mass (kg. $\mathrm{mol}^{-1}$ ) of a gas molecule.

(ii) Laminar flow

$F_{\mathrm{P}, 0}=\frac{\epsilon_{\mathrm{p}} \mu_{\mathrm{p}}}{8 R T} \frac{\vec{r}^{2}}{\eta L} P_{\mathrm{m}}$

Where $F_{\mathrm{P}, 0}$ is the Poiseuille permeation (mol.m $\mathrm{m}^{-2} \cdot \mathrm{s}^{-1} \cdot \mathrm{Pa}^{-1}$ ), $\mu_{\mathrm{p}}$ is the reciprocal tortuosity $(-), \eta$ is the gas viscosity (N.s.m $\left.{ }^{-2}\right), L$ is the thickness $(\mathrm{m})$ of the porous layer and $P_{\mathrm{m}}$ is the mean pressure $(\mathrm{Pa})$.

(iii) Surface diffusion

$J_{\mathrm{S}, 0}=-\rho_{\text {app }} \cdot D_{\mathrm{s}} \cdot \mu_{\mathrm{s}} \frac{\mathrm{d} q}{\mathrm{~d} l}$

where $J_{\mathrm{S}, 0}$ is the surface diffusion flux component $\left(\mathrm{mol} \cdot \mathrm{m}^{-2} \cdot \mathrm{s}^{-1}\right), \rho_{\text {app }}$ is the apparent density $\left(\mathrm{kg} \cdot \mathrm{m}^{-3}\right)$, defined as $\left(1-\epsilon_{\mathrm{p}}\right) \cdot \rho_{\text {cryst }}, D_{\mathrm{S}}$ is the surface diffusion coefficient $\left(\mathrm{m}^{2} . \mathrm{s}^{-1}\right), \mu_{\mathrm{s}}$ is the reciprocal tortuosity $(-)$ and $\mathrm{d} q / \mathrm{d} l$ the surface concentration gradient $\left(\mathrm{mol} . \mathrm{kg}^{-1} \cdot \mathrm{m}^{-1}\right.$ ). The activation energy for diffusion is strongly correlated with the heat of adsorption. Since it is assumed that diffusion takes place by molecules which jump from one site to another, the activation energy is a fraction of the heat of adsorption [36]. This implies that: a) strongly adsorbed molecules are less mobile than weakly adsorbed molecules, and b) that the total flux will decrease as the temperature is increased since the increased diffusivity is overruled by the decrease in surface concentration.

In this paper we will discuss the mechanism of this, so-called activated transport or micropore diffusion, and its relation to membrane structure. This analysis, which is the third part of our extensive gas transport study [20], will focus on sol-gel derived microporous ceramic membranes. Permeation measurements of single gases and separation experiments of binary gas mixtures through microporous silica modified ceramic membranes have been presented earlier $[20,21]$ in Part I of our study. These results will be integrated with sorption data on non-supported silica membranes from
Part II $[20,32]$. The phenomenological and theoretical backgrounds used for the analysis are given in the next section. A model is presented which incorporates experimental data into a microscopic description of gas transport routes in microporous membranes. A very important step in the analysis is the assessment of a possible sorption barrier to transport.

Since small pore zeolites have appertures in the same order than the pore size of microporous silica, and consist of similar molecular building blocks ( $\mathrm{Si}-\mathrm{O}-\mathrm{Si}$ units), comparison of gas transport data with these materials is usefull and relevant. In the discussion the results of our analysis on gas transport in microporous silica will be evaluated using gas transport data in some zeolites. This allows us to give an assessment of the pore size based on transport through supported microporous membranes.

\section{Phenomenological and theoretical description of gas transport in microporous materials}

The description of gas transport and separation in microporous materials is divided in three parts. First, we will describe the contributions of sorption and micropore diffusion on the total transport. Based on the analysis of the interface processes, an equation for gas permeation is derived which includes both sorption and micropore diffusion. It is shown that the activation energy for permeation is an apparent one, which consists of both the isosteric heat of adsorption and the activation energy for micropore diffusion. If interface processes are not rate determining, calculation of the activation energy for micropore diffusion is possible, assuming that the contribution to the gas flux from defects can be ignored. Secondly, we will discuss the influence of pore size on micropore diffusion, and thirdly, the implications of pore size on gas separation will be discussed.

\subsection{Modelling of gas transport in microporous materials. A description of gas transport by an integrated sorption-diffusion process}

\section{General description of micropore diffusion}

Generally, diffusion of matter in gases, liquids or solids can be described by Fick's first law: 


$$
J=-D_{\mathrm{c}}(q) \cdot \frac{\delta q}{\delta x}
$$

where $J$ is the flux, $q$ is the concentration of the adsorbed diffusing species in the porous system, $D_{\mathrm{c}}(q)$ is the intracrystalline diffusivity, which is in general dependent on the concentration and $\delta q / \delta x$ is the concentration gradient. This equation implicitly contains the assumption that the driving force for transport is the concentration gradient. It is clear, however, that the true driving force must be the gradient of the chemical potential $(\mu)[33,34]$.

A general way to describe gas transport in micropores is then given by:

$J=-B_{\mathrm{c}}(q) q \frac{\delta \mu}{\delta x}$

where $q$ is the concentration of the diffusing species in the micropores of the material, and $B_{\mathrm{c}}(q)$ the mobility. The relation between $B_{\mathrm{c}}(q)$ and the Fickian diffusivity $D_{\mathrm{c}}(q)$, which is derived by assuming equilibrium between the adsorbed phase and an ideal vapor phase $\left(\mu=\mu_{0}+R T \ln (P)\right)$, is given by $[33,34]$ :

$D_{c}(q)=B_{c}(q) R T \frac{\mathrm{d}(\ln P)}{\mathrm{d}(\ln q)}=D_{0}(q) \frac{\mathrm{d}(\ln P)}{\mathrm{d}(\ln q)}$

where $D_{0}(q)$ is the intrinsic diffusivity. Transport can be now be described by:

$J=-D_{0}(q)\left(\frac{\mathrm{d}(\ln P)}{\mathrm{d}(\ln q)}\right) \frac{\mathrm{d} q}{\mathrm{~d} x}$

It can be seen that if Henry's law is obeyed $(\mathrm{d}(\ln P) /$ $\mathrm{d}(\ln q)=1)$, the diffusivity approaches a limiting value, $D_{0}(q)$, and Fick's first law is obtained.

\section{Analysis of sorption and interface processes}

A theoretical model for gas transport in microporous zeolite crystals, with a fixed pore size, is proposed by Barrer [37]. The intracrystalline flux through a zeolite crystal (micropore diffusion), is given by (9):

$J_{\mathrm{id}}=\frac{s \cdot k_{1}}{n-1} \exp \left(\frac{-E_{1}}{R T}\right) \cdot\left[\theta_{1}-\theta_{n}\right]$

where $s$ is the number of pores per cross-section area normal to the direction of $J, n$ is the number of diffusion steps in the pore (if $n$ is large: $n-1 \approx l / d$ where $l$ is the membrane thickness and $d$ the jump distance), $\theta_{1}$ is the occupation degree in the pore entrance, $\theta_{\mathrm{n}}$ is the occupation degree in the pore exit at the low pressure side of the pore. The rate constant for jumping across energy barriers within the crystal (micropore diffusion) is $k$ :

$k=k_{1} \exp \left(\frac{-E_{1}}{R T}\right)$

where $k_{1}$ is the pre-exponential constant and $E_{1}$ is the activation energy. For $k$, the intra-crystalline diffusivity, Fick's first law (analogous to (5)) is implicitly used.

$\theta_{1}$ and $\theta_{n}$, however, are steady-state fractions, rather than equilibrium ones. To describe the deviation from equilibrium, the interface processes have to be analyzed. The model describes the flux $J$ to take place by a parallel process, where F1.J represents the fraction of gas molecules which enter the micropore directly, without being adsorbed first, and $\mathrm{F} 2 . J$ represents the fraction which is first adsorbed at the external surface. A schematic presentation of the model is given in Fig. 1.

The different steps in the model are:

a) Gas phase transport to the micropore, which can take place by two parallel fluxes: (i) via an externally adsorbed layer, flux F2.J, consisting of fraction $\mathrm{f} 1 . J$ (flux direct to adsorption sites $\theta_{0}$ near pore mouth) and fraction $\mathrm{f} 2 . J$ (flux to adsorption sites $\theta_{0, \text { surf. }}$ on the surface, which involves a surface diffusion step from sites $\theta_{0 \text {,surf. }}$ to sites $\theta_{0}$ ), or (ii) directly from the gas phase to the pore entrance (flux $\mathrm{F} 1 . J$ ).

b) Entrance of externally adsorbed molecules at site $\theta_{0}(\mathrm{~F} 2 . J)$ to site $\theta_{1}$, and direct entrance of gas phase molecules (F1.J) to site $\theta_{1}$, where site $\theta_{1}$ is

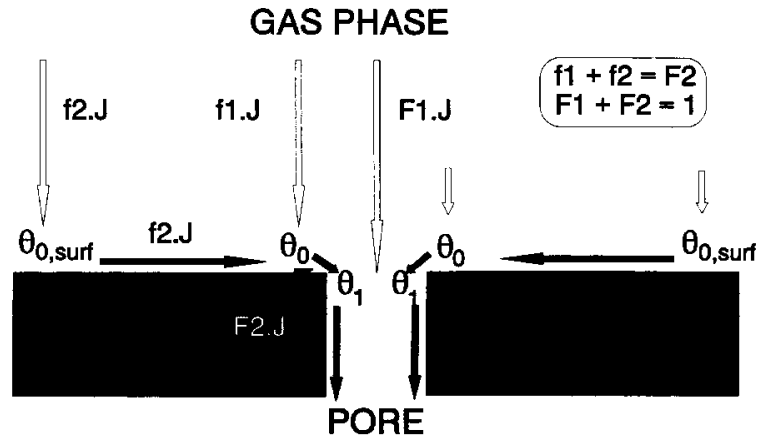

Fig. 1. Model of gas transport in zeolite crystal membranes after Barrer [37]. Flux $J$ consists of fractions $F 1 . J$ (direct from gas phase to site $\theta_{1}$ ) and $F 2 J$ (via an externally adsorbed layer to site $\theta_{1}$ ). 
the first site in the micropore. This process may require the passage of an energy barrier.

c) Micropore diffusion in the pores $(J)$

d) Desorption from the pore to the external surface (at site $n$ ) or directly to the gas phase.

e) Desorption from the external surface to the gas phase.

The potential energy curves for these different steps are given in Fig. 2. $E_{1}$ is the activation energy for micropore diffusion, $\Delta E$ is the energy difference between the gas phase and the molecules present in the micropores, which is a heat of desorption and is equal to $-q^{\mathrm{st}}, E_{\mathrm{s}}$ is the activation energy for pore entrance from the external surface, and $\Delta E_{\mathrm{s}}$ is the energy difference between the molecules adsorbed on the external surface and the gas phase.

The steady state fluxes $\mathrm{F} 1 . J$ and $\mathrm{F} 2 . J$, from the gas phase to site $\theta_{1}$ and from sites $\theta_{0}$ to $\theta_{1}$ respectively, are given by the mass balance Eqs. (11) and (12), respectively:

$$
\begin{aligned}
& \mathrm{F} 1 . J= s . k_{a} C_{\mathrm{g}, 0}\left(1-\theta_{1}\right)-s . k_{b} \\
& \exp (-\Delta E / R T) \theta_{1} \\
& \mathrm{~F} 2 . J= s . k_{c} \exp \left(-E_{\mathrm{s}} / R T\right) \theta_{0}\left(1-\theta_{1}\right)-s . k_{d} \\
& \exp \left(-\left(\Delta E-\Delta E_{\mathrm{s}}+E_{\mathrm{s}}\right) / R T\right) \theta_{1}\left(1-\theta_{0}\right)
\end{aligned}
$$

where $C_{\mathrm{g}, 0}$ is the gas phase concentration, $k_{a-d}$ are reaction rate constants. It can be seen that for leaving the pore (from $\theta_{1}$ to the gas phase) energy barriers $(\Delta E)$ and $\left(\Delta E-\Delta E_{\mathrm{s}}+E_{\mathrm{s}}\right)$ have to be passed. At site $\theta_{n}$, situated at the low pressure side of the membrane, analogous equations can be derived.

When the interface processes are taken into account, a relation can be derived for $J_{\text {id }} / J$, where $J_{\text {id }}$ is given by Eq. (9) for the ideal case that interface processes do not play a role ( $\theta_{1}$ and $\theta_{n}$ are substituted by $\theta_{1, \text { eq }}$

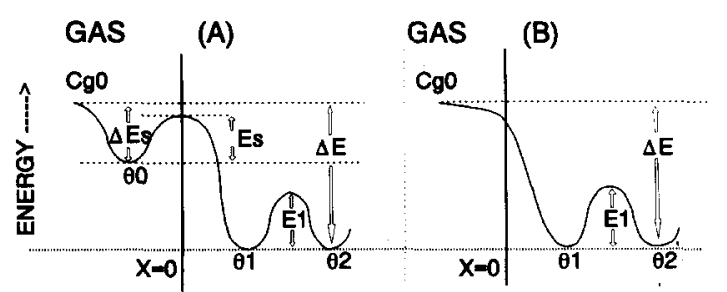

Fig. 2. Potential energy curve of gas transport in zeolite crystal membranes after Barrer [37], situation (A) corresponds to F2.J, situation (B) corresponds to $\mathrm{F} 1 . J$. and $\theta_{n, \mathrm{eq}}$ respectively). In the case that external adsorption obeys Henry's law, $J_{\mathrm{id}} / J$ can be estimated as a function of the different energy barriers, membrane thickness, pressure and temperature by [37]:

$\frac{J_{\text {id }}}{J}=1+\left(\frac{d}{l}\right)\left(2-\theta_{1, \mathrm{eq}}-\theta_{n, \mathrm{eq}}\right) \exp \left(\frac{\delta \Delta E}{R T}\right)$

where $d$ is the jump distance for micropore diffusion (in the order of $5 \times 10^{-10} \mathrm{~m}$ [37]) and $l$ is the membrane thickness. $\delta \Delta E=\left(E_{\mathrm{s}}+\Delta E-\Delta E_{\mathrm{s}}-E_{1}\right)$ for surface transport $(\mathrm{F} 2 . J)$, and in the case that surface transport is not significant, so only (F1.J) remains: $\delta \Delta E=\Delta E-E_{1}$. If both external and internal sorption obey Henry's Law [37]:

$\frac{J_{\text {id }}}{J}=1+2\left(\frac{d}{l}\right) \exp \left(\frac{\delta \Delta E}{R T}\right)$

From these equations it can be clearly seen that interface processes become less significant if the surface barrier is low (low $\Delta E_{\mathrm{s}}$ and/or $E_{\mathrm{s}}$ ), for large crystals or thick membranes (d/l small) and high temperatures.

\section{Integration of sorption and diffusion processes}

In the preceding analysis of gas transport in microporous systems it is shown that transport can be described by Fick's first law (Eq. 5) if sorption takes place according to Henry's Law. The amount gas adsorbed per $\mathrm{m}^{3}$ solid $\left(c\right.$ in mol. $\mathrm{m}^{-3}$ ), can be expressed by:

$c=\rho . K . P$

where $K$ is Henry's constant (mol.kg $\left.{ }^{-1} \cdot \mathrm{Pa}^{-1}\right), P$ is the pressure $(\mathrm{Pa})$ and $\rho$ is the top layer skeletal density $\left(\mathrm{kg} \cdot \mathrm{m}^{-3}\right)$. The concentration sorbate $q$ in the micropores of the top layer material with porosity $\epsilon_{\mathrm{p}}\left(V_{\text {micropores }} /\left(V_{\text {micropores }}+V_{\text {solid }}\right)\right.$ is then:

$q=c \cdot \frac{V_{\text {solid }}}{V_{\text {micropores }}}=c \cdot \frac{1-\epsilon_{\mathrm{p}}}{\epsilon_{\mathrm{p}}}$

The following relation for the activated flux $J$ $\left(\mathrm{mol} \cdot \mathrm{m}^{-2} \cdot \mathrm{s}^{-1}\right.$ ), can be then derived:

$J=-D \cdot \frac{\mathrm{d} q}{\mathrm{~d} x}=-D \cdot \frac{1-\epsilon_{\mathrm{p}}}{\epsilon_{\mathrm{p}}} \cdot \rho \cdot K \cdot \frac{\Delta P}{l}$

where $l$ is the membrane thickness ( $\mathrm{m})$ and $D$ is the micropore diffusion coefficient $\left(\mathrm{m}^{2} \cdot \mathrm{s}^{-1}\right)$. 
Incorporation of the temperature dependency of $K$ and $D$ [32] gives:

$J=-\frac{\rho}{l} \frac{1-\epsilon_{\mathrm{P}}}{\epsilon_{\mathrm{p}}} D_{0} \exp \left(\frac{-E_{1}}{R T}\right) K_{0} \exp \left(\frac{q_{\mathrm{st}}}{R T}\right) \Delta P$

where $D_{0}\left(\mathrm{~m}^{2} . \mathrm{s}^{-1}\right)$ is the mean intrinsic diffusion coefficient for micropore diffusion, and $K_{0}$ is the intrinsic Henry constant [32].

However, the product $\left(\left(1-\epsilon_{\mathrm{p}}\right) / \epsilon_{\mathrm{p}}\right) \cdot D_{0} \cdot K_{0}$ cannot be separated easily to determine the value of $D_{0}$, since the exact porosity $\epsilon$ of the supported membrane is difficult to determine [17]. This affects the value of $K_{0}$, since these values are determined from non-supported membranes, as well [32]. Also it has to be recognized that gas transport through the solid state is neglected.

"The influence of interface processes can be analyzed using Eqs. (13) and (14), and the isosteric heat of adsorption $\left(q^{\text {st }}\right)$ can be determined from sorption experiments. Unfortunately, the surface barriers $\Delta E_{\mathrm{s}}$ and $E_{\mathrm{s}}$ can not be determined from separate experiments, which implies that the determination of $E_{1}$ is possible only if:

(i) external adsorption does not play a role, which implies that transport takes place by route F1.J.

(ii) physically reasonable approximations of $\Delta E_{\mathrm{s}}$ and $E_{\mathrm{s}}$ are known. Since sorption is strongly enhanced in the micropores, compared to a 'free' surface, as will be discussed in the next paragraph, $\Delta E_{\mathrm{s}}$ (the adsorption energy on the external surface) cannot be higher than $\Delta E$ (the sorption energy in the micropores).

If the interface processes are not rate determining indeed, then $E_{1}$ can be calculated from the apparent activation energy for permeation $\left(E_{\text {act }}\right)$ by:

$E_{1}=E_{\text {act. }}-\Delta E$

where $\Delta E=-q^{\text {st }}$ (the isosteric heat of adsorption), and $E_{\text {act }}$ is calculated from Eq. (1). Note, that it is implicitly assumed that the contribution of the external surface on the calculated isosteric heat of adsorption can be neglected.

\subsection{Analysis of adsorption potentials in microporous materials}

The origin of the activation of gas transport in micropores can be analyzed by the evolution of the adsorption potentials of a gas molecule in pores with decreasing pore diameter. An extensive analysis of the potential functions in micropores is given by Everett and Powl [38]. In their paper, quantitative calculations are presented of the enhancement of (Lennard-Jones) adsorption potentials of a gas molecule as function of the distance of opposite and neighbouring pore surfaces.

In Fig. 3, a schematic picture, based on the calculations of Everett and Powl [38], is presented in order to illustrate the relation between pore size and adsorption potential for situations representative for microporous membranes.

In the upper part, two fictive molecules $A$ and $B$ are shown in the pore of an oxidic material. The diameter of molecule $\mathrm{B}$ is 1.2 times the diameter of molecule $\mathrm{A}$. For example, this is the case for $\mathrm{O}_{2} / \mathrm{H}_{2}$, as can be seen in Table 1 [39]. The pore wall is located at the center of the surface oxygen ions; the effective pore diameter $D_{\text {eff }}\left(=2 R-\sigma_{\text {surface oxygen, }}\right.$, where $\sigma_{\text {surface oxygen }}=0.276$ $\mathrm{nm}[40]$ ) is given between the dotted lines.

In the lower part, the enhancement of the $(10: 4)$ Lennard-Jones adsorption potential is schematically ${ }^{2}$ given as function of the relative distance from the pore center for 5 relative pore sizes, and for cylindrical pore geometry. $\epsilon_{\mathrm{A}}=(z) / \epsilon_{\mathrm{A} 1}^{*}$ is the ratio of the LennardJones potential in the pore $\left(\epsilon_{\mathrm{A}}=(z)\right)$, and $\epsilon_{\mathrm{A} 1}^{*}$, the absolute value of the potential minimum of the Len-

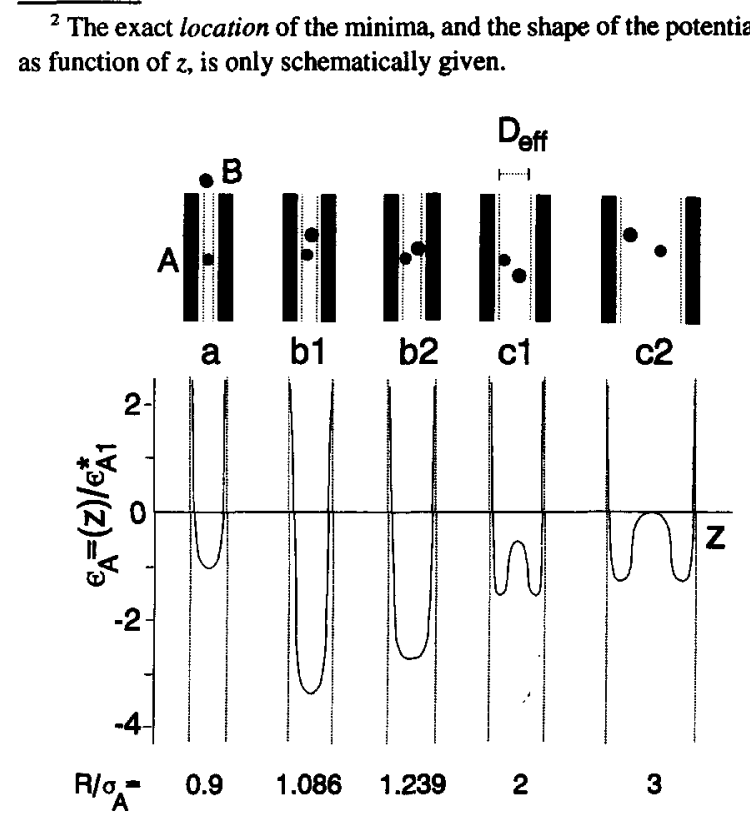

Fig. 3. Different pore size regimes related with molecular size; (10:4) potentials (cylindrical geometry) for molecule A. 
Table 1

Kinetic diameter of some selected gases, according to [39]

\begin{tabular}{ll}
\hline Gas & Kinetic diameter $\sigma(\mathrm{nm})$ \\
\hline $\mathrm{He}$ & 0.26 \\
$\mathrm{H}_{2} \mathrm{O}$ & 0.265 \\
$\mathrm{H}_{2}$ & 0.289 \\
$\mathrm{CO}_{2}$ & 0.33 \\
$\mathrm{O}_{2}$ & 0.346 \\
$\mathrm{~N}_{2}$ & 0.364 \\
$\mathrm{CH}_{4}$ & 0.38 \\
$\mathrm{C}_{3} \mathrm{H}_{8}$ & 0.43 \\
iso- & $\mathrm{C}_{4} \mathrm{H}_{10}$ \\
$\mathrm{Benzene}$ & 0.5 \\
$\mathrm{CCl}_{4}$ & 0.585 \\
\hline
\end{tabular}

nard-Jones potential on a 'free' surface, where $z$ is the distance from the center of the pore. The relative pore size is expressed as $R / \sigma_{\mathrm{A}}$, where $R$ is the pore radius and $\sigma_{\mathrm{A}}$ the kinetic diameter of molecule $\mathrm{A}$. Note that by expressing the potentials as $\epsilon_{\mathrm{A}}=(z) / \epsilon_{\mathrm{A} 1}^{*}$ a dimensionless potential is obtained, which then allows comparison of situations for different sorbent/sorbate combinations.

It can be seen that the potential shows a double minimum at larger wall distances (situations $\mathrm{c} 1$ and $\mathrm{c2}$ ), which coalesce to a single minimum at smaller wall distances. For the (10:4) Lennard-Jones potentials, and cylindrical pore geometry, the point where the double minimum changes to a single minimum is located at $R / \sigma=1.239$ (situation b2). For slit-shaped pores this point is at $d / \sigma=1.14$. The maximum value of $\epsilon=(z) / \epsilon_{1}^{*}$, which is the maximum enhancement of the potential minimum compared to a 'free' surface, is for the (10:4) potential and cylindrical geometry at $R /$ $\sigma=1.086$, and the maximum enhancement is a factor 3.388 ( situation b1). For slit shape geometry the maximum enhancement is found at $d / \sigma=1$, where the enhancement is a factor 2 . Further decrease of the pore radius causes a strong increase (less negative) of the potential, which results in a non-permeable pore if $\epsilon>0$. It is clear, that the interaction of opposing and neighbouring walls is much stronger for cylindrical pores than for slit shaped pores.

Physically this model shows that the adsorption energy in micropores is strongly enhanced with respect to a 'free' surface, where the enhancement is dependent on pore size and pore shape. For relatively wide pores, these effects can be quite significant; for cylindrical pore geometry an enhancement of around $30-50 \%$ is present at $R / \sigma \approx 3$ (pore diameter $\approx 6$ times molecule diameter) [38].

\subsection{Gas separation in microporous materials}

For the application of microporous systems in gas separation processes, the above described analysis of diffusion in micropores has to be extended with a quantitative model where different regions in separation mechanisms are discriminated. Some aspects which have not been discussed before are: True molecular sieving (which refers to exclusion, see below) and the possibility of different gas molecules passing each other within a pore.

In our model, a distinction is made in three pore size regions, where the relative pore size rather than the absolute pore size is important. The pore diameter is defined as $d$ and the size of the gas molecules $\mathrm{A}$ and $\mathrm{B}$ is given by the kinetic diameters $\sigma_{\mathrm{A}}$ and $\sigma_{\mathrm{B}}$, where $\sigma_{\mathrm{A}}<\sigma_{\mathrm{B}}$. The pore size regions will be considered below, where we refer to the schematic presentation given in Fig. 3:

a) $\sigma_{\mathrm{A}}<d<\sigma_{\mathrm{B}}$ (situation a)

This is the simplest case and refers to true molecular sieving. Molecule B can not enter the pore and only molecule A will permeate. This results in an infinite separation factor for $\mathrm{A}$, where the permeation rate is only dependent on the micropore diffusion rate of $\mathrm{A}$, and, in the case external surface sorption is rate determining, on the surface concentration. The surface concentration of $\mathrm{A}$ and consequently its permeation, however, may be influenced by $B$ if strong adsorption of $B$ takes place on the external surface of the material.

b) $\sigma_{\mathrm{B}}<d<\left(\sigma_{\mathrm{A}}+\sigma_{\mathrm{B}}\right)$ (situation b1 and b2)

In this pore size regime, with maximum absolute pore diameters in the order of $1-1.2 \mathrm{~nm}$, both $A$ and $B$ can enter the pore. Since the pore size is still very small, both gas molecules will show activated micropore diffusion. In situation b1, molecule A shows a maximum enhancement of the potential minimum. The potential for molecule $B$ will be less negative, comparable with situation a for A. Since the pore morphology is ideally cylindrical, the molecules can not pass each other, which then implies that the diffusion rate is determined by the slowest moving component.

Situation b2 represents the point where the single minimum of the potential of molecule A will turn to a 
double minimum. At this point, $d=2.478 \times \sigma_{\mathrm{A}}$, which means that for this example the diameter $d$ is slightly higher than $\sigma_{\mathrm{A}}+\sigma_{\mathrm{B}}\left(=2.2 \times \sigma_{\mathrm{A}}\right)$. The effective pore diameter $D_{\text {eff }}$, however is smaller, and also in this case, molecules will probably not be able to pass each other.

In many small pore zeolites and carbon molecular sieves, however, the pores are not ideally cylindrical, and/or wider regions (supercages or cross points of channels for zeolites) are present. The smallest constriction (window diameter in zeolites) determines the diffusion rate. In the larger cages, however, the molecules can pass freely. The same holds for slit-shaped pore geometry, which is the case for most microporous carbons, provided the concentration is not too high. If indeed the molecules cannot pass each other, then selective permeation is determined by differences in sorption characteristics.

c) $\left(\sigma_{\mathrm{A}}+\sigma_{\mathrm{B}}\right)<d<\approx 2 \mathrm{~nm}$ ( situation c1 and c2)

In this pore size region, $A$ and $B$ can pass each other regardless the pore morphology. For the case that molecule A represents hydrogen $(\sigma=0.289 \mathrm{~nm})$, the pore diameter in situation $\mathrm{c} 2$ is $1.73 \mathrm{~nm}$, which is still in the micropore region.

The increasing relative pore size implies that enhancement of the adsorption potentials by the opposing walls will decrease, and for larger pore sizes, the influence of the wall potential in the center of the pore is not present any more. Free gas diffusion will therefore take place in the center part of larger pores. Adsorbed molecules will diffuse along the surface, where the heat of adsorption ( $\equiv$ surface potential) is still enhanced by the opposing wall, resulting in a slightly enhanced potential. Both differences in micropore diffusivity and sorption determine the selectivity in the permeation.

d) $d>\approx 2 \mathrm{~nm}$

This is the mesopore region, activated transport does not take place, since both surface diffusion, Knudsen diffusion and multilayer diffusion decrease as function of temperature.

\section{Membrane characteristics and experimental procedures}

\subsection{Membrane synthesis and characteristics}

$\gamma$-Alumina membranes were prepared by a dip coating process of $\alpha$-alumina supports (disc-shape, diam- eter $39 \mathrm{~mm}$, thickness $2 \mathrm{~mm}$, mean pore radius $160 \mathrm{~nm}$, porosity $50 \%$, surface roughness around $40 \mathrm{~nm}$ ) in boehmite $(\gamma$-AlOOH) dip solutions, followed by drying in a climate chamber $\left(40^{\circ} \mathrm{C}, 60 \%\right.$ R.H. $)$ for $3 \mathrm{~h}$ and subsequent calcination for $3 \mathrm{~h}$ at $600^{\circ} \mathrm{C}$. To repair possible pin-holes, this procedure is repeated twice for standard $\gamma$-alumina membranes. An extensive description of this process is given earlier [17]. The final toplayer thickness is in the order of 7-10 $\mu \mathrm{m}$, with a mean pore diameter of around $5 \mathrm{~nm}$.

These membranes were modified with polymeric silica sols to obtain a microporous top-layer. Polymeric $\mathrm{SiO}_{2}$ sols were prepared by acid catalyzed hydrolysis of tetra-ethyl-ortho-silicate (TEOS) in ethanol with standard molar ratios of TEOS-water- $\mathrm{HNO}_{3}$-ethanol of 1-6.4-0.085-3.8 (sample code: $\mathrm{StSiO}_{2}$ ). Detailed descriptions of the sol synthesis and membrane formation are given elsewhere $[17,19,41]$.

Due to the very mild synthesis conditions and the application of on acid catalyst, weakly branched oligomeric sols are obtained, with typical fractal dimensions of $1.4-1.5$ and radii of gyration of $\approx 2.0 \mathrm{~nm}$ [19,41]. During consolidation of these sol units (layer formation), interpenetration occurs, resulting in a microporous structure. From nitrogen adsorption experiments with non-supported membranes it was found that the final pore size distribution is bimodal, with a strong maximum at an effective diameter of 0.5 $\mathrm{nm}$ and a weak maximum at $0.75 \mathrm{~nm}[20,42]$.

\subsection{Permeation, separation and sorption experimental procedures}

Gas permeation experiments were performed in a temperature range from 25 to $250^{\circ} \mathrm{C}$ by measurement of dead-end permeation, as described in detail in [21]. The permeation $(F)^{3}$ is defined as the ratio of the transmission rate or flux (quantity of gas crossing a unit area in unit time; in mol.m $\mathrm{m}^{-2} \cdot \mathrm{s}^{-1}$ ) and the (partial) pressure difference in mol.m ${ }^{-2} \cdot \mathrm{s}^{-1} \cdot \mathrm{Pa}^{-1}$ $\left(\equiv 1.344 \times 10^{7} \quad \mathrm{ml} \cdot \mathrm{min}^{-1} \cdot \mathrm{cm}^{-2} \cdot \mathrm{bar}^{-1} \equiv 1.93 \times 10^{8}\right.$ $\mathrm{m}^{3} \cdot \mathrm{m}^{-2} \cdot$ day $\left.^{-1} \cdot \mathrm{bar}^{-1}\right)$. The apparent activation energy

\footnotetext{
${ }^{3}$ The permeation implicitly contains the layer thickness $(l)$ of the membrane, and is therefore not a real material constant. The socalled permeability, defined as the product $F . l$ in units mol.m.m $\mathrm{m}^{-2} \cdot \mathrm{s}^{-1} \cdot \mathrm{Pa}^{-1}$, corrects for layer thickness (provided it is known accurately). Unfortunately the meaning of permeation and permeability is often confused in literature.
} 
for permeation is calculated according to Eq. (1). Corrections for support ( $\gamma$-alumina membrane) influence on the permeation of the microporous top-layer have to be performed to calculate the real pressure drop over the top layer. These corrections were performed by the series model, which requires knowledge of the permeation characteristics of the support $\left(F_{\text {Support }}\right)$. The permeation is then regarded as a reciprocal resistance, where the top-layer permeation $F_{\text {Toplayer }}$ can be calculated from the membrane permeation $F_{\text {Total }}$ according to:

$$
\frac{1}{F_{\text {Toplayer }}}=\frac{1}{F_{\text {Total }}}-\frac{1}{F_{\text {Support }}}
$$

An extensive description of the calculation method and influence on the calculated permeation rates is given elsewhere [17].

Counter-current separation experiments [21], with binary gas mixtures and using Argon as sweep-gas at the low pressure side, are performed at temperatures ranging from 25 to $300^{\circ} \mathrm{C}$. Typical gas flow rates are $200 \mathrm{ml} / \mathrm{min}$ for the feed (at a pressure of around 2 bar) and $150 \mathrm{ml} / \mathrm{min}$ for the sweep gas. The low pressure side was connected to a vacuum pump, leading to a down-stream pressure of 0.8 bar. The ideal separation factor $(\alpha)$ is defined as the enrichment factor of one component in the permeate compared to the feed composition, according to:

$$
\alpha=\frac{y}{1-y} \frac{1-x}{x}
$$

where $y$ is the molar fraction of the faster permeating component in the permeate and $x$ is the molar fraction of this component in the feed.

Sorption experiments on non-supported microporous membranes are performed using both volumetric and gravimetric sorption equipment, as described extensively in Part I of our study [32]. Important characteristics to be obtained from sorption experiments are the Henry coefficient and the isosteric heat of adsorption. The Henry adsorption isotherm can be expressed in experimental parameters by:

$n=K \cdot P$

where $K$ is Henry's constant (mol. $\mathrm{kg}^{-1} \cdot \mathrm{Pa}^{-1}$ ), $P$ is the pressure $(\mathrm{Pa})$ and $n$ is the amount adsorbed $\left(\right.$ mol. $\left.\mathrm{kg}^{-1}\right)$. The temperature dependency of the adsorption isotherms is used to derive the isosteric heat of adsorption. An equation similar to the ClausiusClapeyron equation for a phase change in a one component system can be used to calculate the isosteric heat of adsorption $q^{\text {st: }}$

$\left(\frac{\delta(\ln P)}{\delta(1 / T)}\right)_{n}=-\frac{q^{\mathrm{st}}}{R}$

where $-q^{\mathrm{st}}$ is equal to the enthalpy change $\left(\mathrm{kJ} \cdot \mathrm{mol}^{-1}\right)$ upon adsorption, $R$ is the gas constant $\left(\mathrm{kJ} \cdot \mathrm{mol}^{-1} \cdot \mathrm{K}^{-1}\right), \quad n$ is the amount adsorbed (mol.kg ${ }^{-1}$ ), $P$ is the absolute pressure $(\mathrm{Pa})$ and $T$ is the adsorption temperature $(\mathrm{K})$. From this equation, it is clear that at a certain constant amount adsorbed, a plot of $\ln (P)$ versus $1 / T$ will yield a straight line with slope $-\left(q_{\mathrm{st}} / R\right)$.

\section{Typical transport and sorption results}

\subsection{Sorption results}

Sorption experiments were performed with $\mathrm{H}_{2}, \mathrm{CO}_{2}$, $\mathrm{CH}_{4}$ and iso- $\mathrm{C}_{4} \mathrm{H}_{10}$ on non-supported silica. A representative example of the sorption behavior for these gases as function of pressure and temperature is given in Fig. 4 for sub-atmospheric sorption of $\mathrm{CO}_{2}$ on silica. The isotherms are given by plotting the amount adsorbed in $\mathrm{ml}(\mathrm{STP}) \cdot \mathrm{g}^{-1}$ versus pressure $(\mathrm{Pa})$, where $1 \mathrm{ml}(\mathrm{STP}) \cdot \mathrm{g}^{-1} \equiv 0.045 \mathrm{~mol} . \mathrm{kg}^{-1}$. As can be seen, the adsorption capacity decreases strongly as function of temperature. The isotherms are Langmuir-type at 273

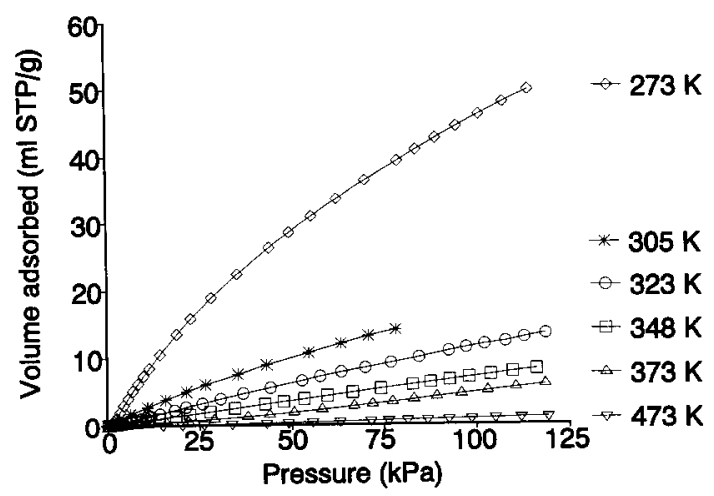

Fig. 4. Sub-atmospheric $\mathrm{CO}_{2}$ adsorption isotherms on $\mathrm{SiO}_{2}$, obtained with the volumetric set-up and the gravimetric set-up ( $305 \mathrm{~K}$ ). 


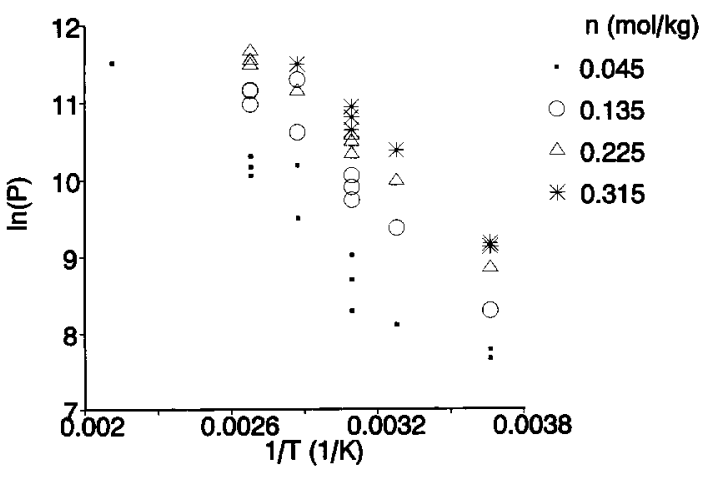

Fig. 5. $\mathrm{CO}_{2}$ adsorption isosteres on silica. $P$ in units of $\mathrm{Pa}$.

and $305 \mathrm{~K}$. At higher temperatures the isotherms are practically linear, which implies that they obey Henry's law over the whole pressure range used. Since the total adsorption capacity for the isotherms higher than 348 $\mathrm{K}$ is low, isosteres can only be calculated up to around $8 \mathrm{ml}(\mathrm{STP}) \cdot \mathrm{g}^{-1}$ ( $\left.\equiv 0.36 \mathrm{~mol} \cdot \mathrm{kg}^{-1}\right)$. The surface coverage is then very low, with an upper limit of around $20 \%$ as can be derived from the isotherm at $273 \mathrm{~K}$. Four representative $\mathrm{CO}_{2}$ adsorption isosteres are given in Fig. 5. The calculated isosteric heat of adsorption is $22.3 \mathrm{~kJ} . \mathrm{mol}^{-1}$, and was practically independent of amount adsorbed, which is indicative for the absence of stronger adsorbate-adsorbate interactions at high surface coverages.

The sorption capacity on silica at ambient temperatures has found to be considerable for $\mathrm{CO}_{2}$ and iso$\mathrm{C}_{4} \mathrm{H}_{10}$, but extremely low for $\mathrm{H}_{2}$ and $\mathrm{CH}_{4}$. The weakly adsorbing nature of the latter two gases is also clearly expressed by low isosteric heats of adsorption. An overview of the results is given in Table 2. Calculated Henry constants and the isosteric heats of adsorption are given for $\mathrm{CO}_{2}, \mathrm{CH}_{4}, \mathrm{H}_{2}$ and iso- $\mathrm{C}_{4} \mathrm{H}_{10}$ sorption on silica. Also the limiting temperature is given for which the isotherm can be classified as Henry-type in the sub-atmospheric pressure range $(P<125 \mathrm{kPa})$. It can be clearly seen that, for example, the total amount adsorbed for $\mathrm{H}_{2}$ is more than 2 decades lower than for $\mathrm{CO}_{2}$ at $273 \mathrm{~K}$, and even at $473 \mathrm{~K}$ the $\mathrm{CO}_{2}$ amount has not decreased to the low level obtained for $\mathrm{H}_{2}$ sorption. Due to the high amount adsorbed and the high isosteric heat of adsorption for $\mathrm{CO}_{2}$ and iso- $\mathrm{C}_{4} \mathrm{H}_{10}$ it can be expected that adsorption phenomena may play an important role in gas transport. The influence of sorption phenomena for the weakly adsorbing gases $\mathrm{H}_{2}$ and $\mathrm{CH}_{4}$ will be less important. For practical applications, high pressure data is important since this enables us to evaluate transport for economically interesting conditions. High pressure sorption experiments with $\mathrm{CO}_{2}$ and $\mathrm{CH}_{4}$ showed that for $\mathrm{CO}_{2}$, Henry adsorption takes place up to 15 bar at $373 \mathrm{~K}$. For $\mathrm{CH}_{4}$, Henry's Law is followed for pressures up to $\approx 8$ bar at $323 \mathrm{~K}$.

\subsection{Permeation results}

Typical $\mathrm{H}_{2}$ and $\mathrm{CO}_{2}$ permeation results for a high quality silica modified membrane (code Al3-Sil-B) are shown in Figs. 6 and 7. Both the $\mathrm{H}_{2}$ permeation and the $\mathrm{CO}_{2}$ permeation are activated. This indicates that an effective modification towards micropore diffusion is obtained, since according to Knudsen diffusion, the permeation should decrease as the temperature is increased (Eq. (2)). The gas permeation of the membranes ( $\equiv$ silica modified $\gamma$-alumina $+\alpha$-alumina support) is calculated by dividing the flow through the membrane by the product of measurement area (1.911 $\mathrm{cm}^{2}$ ) and pressure difference over the membrane. As shown before $[17,21]$, this is allowed since the flow through the membrane is essentially linearly dependent of pressure under these conditions; the permeation is then independent of pressure.

Table 2

Henry constants $(K)$, isosteric heat of adsorption $\left(q^{\mathrm{st}}\right)$ and lower limiting temperature for Henry sorption behavior $T_{\text {limit,Henry }}$ for $\mathrm{CO}_{2}, \mathrm{CH}_{4}, \mathrm{H}_{2}$ and iso- $\mathrm{C}_{4} \mathrm{H}_{10}$ on silica, obtained from sub-atmospheric adsorption experiments $(P<125 \mathrm{kPa})$

\begin{tabular}{|c|c|c|c|c|c|c|c|c|c|c|}
\hline \multirow[t]{2}{*}{ Gais } & \multirow{2}{*}{$\begin{array}{l}q^{\mathrm{si}} \\
\left(\mathrm{kJ} \cdot \mathrm{mol}^{-1}\right)\end{array}$} & \multirow{2}{*}{$\begin{array}{l}T_{\text {limit_Henry }} \\
(\mathrm{K})\end{array}$} & \multicolumn{8}{|c|}{$K\left(\mathrm{~mol} \cdot \mathrm{kg}^{-1} \cdot \mathrm{Pa}^{-1}\right)$} \\
\hline & & & $77 \mathrm{~K}$ & $194 \mathrm{~K}$ & $273 \mathrm{~K}$ & $303 \mathrm{~K}$ & $323 \mathrm{~K}$ & $348 \mathrm{~K}$ & $373 \mathrm{~K}$ & $473 \mathrm{~K}$ \\
\hline $\mathrm{CO}_{2}$ & 22.3 & 348 & - & - & $3.2 \times 10^{-5}$ & $7.8 \times 10^{-6}$ & $5.9 \times 10^{-6}$ & $3.2 \times 10^{-6}$ & $2.1 \times 10^{-6}$ & $4.8 \times 10^{-7}$ \\
\hline $\mathrm{CH}_{4}$ & 10.3 & 273 & 0.42 & $4.2 \times 10^{-6}$ & $2.3 \times 10^{-6}$ & - & - & - & - & - \\
\hline $\mathrm{H}_{2}$ & 6.1 & 194 & $1.5 \times 10^{-4}$ & $3.7 \times 10^{-7}$ & $1.8 \times 10^{-7}$ & - & - & - & - & - \\
\hline iso- $\mathrm{C}_{4} \mathrm{H}_{10}$ & 22.9 & 373 & - & - & $1.7 \times 10^{-4}$ & - & $2.9 \times 10^{-5}$ & $2.4 \times 10^{-5}$ & $9.4 \times 10^{-6}$ & - \\
\hline
\end{tabular}


However, at $200^{\circ} \mathrm{C}$ the permeation for hydrogen increases weakly as the pressure is increased. The cause for this effect is the stronger support influence. Increasing the temperature results in an increased permeation of the microporous top-layer but a decreased permeation of the support. The relative pressure drop over the support therefore increases, as can be seen easily from Eq. (20). The support permeation, which is mainly determined by Knudsen diffusion, is also weakly pressure dependent since it contains a small contribution of Poisseuille flow. The permeation rates and calculated apparent activation energies, both non-corrected and corrected, are given in Table 3 . The corrected pressure drop over the toplayer $\left(P_{\text {high }}-P_{\text {interface }}\right.$, where $P_{\text {interface }}$ is the pressure at the interface of microporous toplayer and $\gamma$-alumina membrane) is smaller than the pressure drop over the membrane system $\left(P_{\text {high }}-P_{\text {low }}\right)$, as used for the non-corrected data. Correction therefore gives

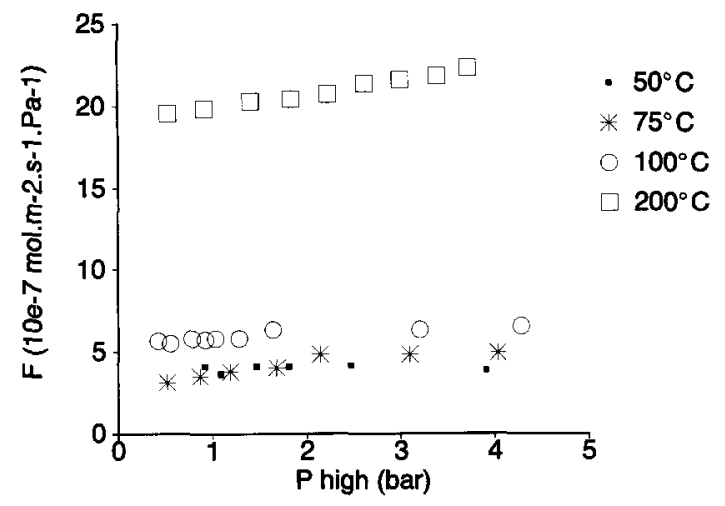

Fig. 6. Hydrogen permeation silica modified membrane Al3-Sil-B.

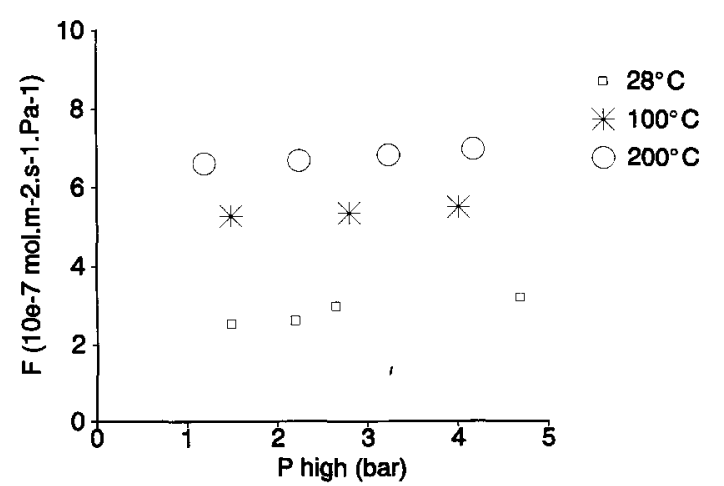

Fig. 7. Carbon dioxide permeation silica modified membrane Al3Sil-B. the true, higher, top-layer permeation. Due to decreased support permeation with temperature, support correction is stronger at higher temperatures, and consequently the corrected activation energy is higher.

In Table 4 and 5 typical permeation results are summarized for silica modified membranes with different activation energies for hydrogen. The $\gamma$-alumina membranes all consist of thrice dipped top-layers, the silica modification was performed in a single step. In Table 4 the apparent activation energies for permeation of hydrogen (non-corrected as well as corrected for support influence) is given as main characteristic. For each of these membranes, the permeation values are given for several gases at $200^{\circ} \mathrm{C}$, to eliminate blocking effects by strong sorption at low temperatures. The general trend is that the permeation rate decreases continuously as function of gas molecule size.

As can be seen, there is a variation in corrected apparent activation energies for hydrogen from $5.8 \mathrm{~kJ} \cdot \mathrm{mol}^{-1}$ to $21.7 \mathrm{~kJ} \mathrm{~mol}^{-1}$. This variation is considered to be caused by differences in membrane quality. Defects (pinholes, cracks or wider micropores) will give rise to a parallel flux through the defect, in which the transport mechanism is mainly determined by Knudsen diffusion and/or surface diffusion. Since permeation according to these mechanisms decreases as function of temperature, the total apparent activation energy is decreased.

In Table 5 the apparent activation energies for the investigated gases are given for the same membranes as discussed in Table 4. Also results from $\mathrm{SiO}_{2} / \mathrm{TiO}_{2}$ ( $10 \mathrm{~mol} \% \mathrm{TiO}_{2}$ ) and $\mathrm{SiO}_{2} / \mathrm{Al}_{2} \mathrm{O}_{3}\left(10 \mathrm{~mol} \% \mathrm{AlO}_{1.5}\right)$ modified membranes (membrane codes 'Al3-SiTi102,Bu', 'Al3-SiTi10-2,Pr' and 'Al3-SiAl10' are abbreviated as 'SiTi-Bu', 'SiTi-Pr' and 'SiAl' respectively), as reported in earlier work [17], have been included. Basically, the transport mechanism of these binary materials is not different compared to pure silica.

Carbon dioxide permeation shows activated transport for membranes characterized by a hydrogen activation energy higher than around $10 \mathrm{~kJ} \cdot \mathrm{mol}^{-1}$ (corrected value). As will be shown hereafter, this is related with the higher isosteric heat of adsorption for carbon dioxide, resulting in a stronger decrease of the concentration in the micropores compared to hydrogen as the temperature in increased.

Some discrepancies can be seen by comparing the transport behavior of oxygen, nitrogen and methane. 
Table 3

Permeation rates and apparent activation energies for silica modified membrane Al3-Si1-B; $P_{\mathrm{ngh}} \approx 3$ bar

\begin{tabular}{llrr}
\hline Gas & Permeation $\left(10^{-7} \mathrm{~mol} \cdot \mathrm{m}^{-2} \cdot \mathrm{s}^{-1} \cdot \mathrm{Pa}^{-1}\right), 50^{\circ} \mathrm{C}\left(\mathrm{H}_{2}\right), 28^{\circ} \mathrm{C}\left(\mathrm{CO}_{2)}\right.$ & $200^{\circ} \mathrm{C}$ & Apparent $E_{\text {act. }}^{\mathrm{a}}\left(\mathrm{kJ} . \mathrm{mol}^{-1}\right)$ \\
\hline $\mathrm{H}_{2}$ & $4.1(4.5)$ & $21.7(52.7)$ & $14.9(21.7)$ \\
$\mathrm{CO}_{2}$ & $2.3(3.0)$ & $6.8(32.3)$ & $6.1(14.9)$ \\
\hline
\end{tabular}

${ }^{a}$ Values between brackets corrected for support influence.

Table 4

Permeation rates $F$ (in $10^{-7} \mathrm{~mol} . \mathrm{m}^{-2} \cdot \mathrm{s}^{-1} \cdot \mathrm{Pa}^{-1}$ ) at $200^{\circ} \mathrm{C}$ for silica modified membranes A13-Si1-A/U with different apparent activation energies $\left(\mathrm{kJ} \cdot \mathrm{mol}^{-1}\right)$ for hydrogen

\begin{tabular}{|c|c|c|c|c|c|c|c|c|c|c|c|}
\hline & \multicolumn{11}{|c|}{ Membrane } \\
\hline & B & C & $\mathrm{D}^{\mathrm{a}}$ & E & $\mathrm{U} 1^{\mathrm{b}}$ & $\mathrm{U} 2^{\mathrm{b}}$ & $\mathrm{F}$ & $A^{c}$ & A & G & $\mathbf{H}$ \\
\hline \multirow{2}{*}{$E_{\mathrm{act}}^{\mathrm{d}}\left(\mathrm{H}_{2}\right)$} & 14.9 & 13.2 & 11 & 8.0 & 7.4 & 6.7 & 5.8 & 5.4 & 5.0 & 4.4 & 3.2 \\
\hline & 21.7 & 16.9 & 12.3 & 11.2 & 10.0 & 11.0 & 8.3 & 11.0 & 7.4 & 5.8 & 6.6 \\
\hline \multicolumn{12}{|l|}{ Gas: } \\
\hline $\mathrm{He}$ & $-^{e}$ & - & - & - & 14.4 & 20.0 & - & - & - & - & - \\
\hline $\mathrm{H}_{2}$ & 21.7 & 16.0 & 13.0 & 18.0 & 17.9 & 22.2 & 21.8 & 23 & 16 & 12.3 & 20.0 \\
\hline $\mathrm{CO}_{2}$ & 6.8 & 5.5 & 3.5 & 5.5 & 5.1 & $6.0^{f}$ & - & 5.2 & 3.0 & - & $8.5^{f}$ \\
\hline $\mathrm{O}_{2}$ & - & - & - & 4.0 & - & - & 5.9 & 5.8 & 1.7 & - & - \\
\hline $\mathrm{N}_{2}$ & - & - & - & - & - & - & 4.7 & - & 0.8 & - & - \\
\hline $\mathrm{CH}_{4}$ & - & - & - & - & - & - & - & 2.4 & 0.36 & - & - \\
\hline i.b. & - & - & - & - & - & - & - & 0.35 & - & - & - \\
\hline
\end{tabular}

aData taken from [17].

'Data taken from Uhlhorn [14].

'Single layer $\gamma$-alumina.

ditalic values corrected for support influence.

ePermeation $\left(10^{-7} \mathrm{~mol} \cdot \mathrm{m}^{-2} \cdot \mathrm{s}^{-1} \cdot \mathrm{Pa}^{-1}\right)$ at $200^{\circ} \mathrm{C}$.

${ }^{\mathrm{f}} 100^{\circ} \mathrm{C}$.

i.b. $=$ iso-butane.

Firstly, it is observed that the activation energy for oxygen permeation is higher than the hydrogen activation energy for membranes with code $A$ and $E$, contrary to membrane F, where it is lower. Secondly, the activation energy for nitrogen is higher than for oxygen or membrane $\mathrm{F}$, contrary to membrane $\mathrm{A}$. Thirdly, the activation energy for methane is higher than for oxygen for membrane $A^{\$}$, contrary to membrane A. Due to the limited amount of data for these gases, the explanation of these observations is difficult. Probably the effects are due to the presence of very small leaks, in the membrane or in the equipment, which will not influence the gas transport behavior of hydrogen and carbon dioxide significantly due to the high intrinsic permeation rates. For the other gases, however, this is not generally true due to their low intrinsic permeation rates.

\subsection{Separation results}

An overview of the separation characteristics of microporous silica modified membranes, is given in Table 6. The membranes are based on three layer $\gamma$ alumina membranes (membrane codes Al3-Si1-..) and a few experiments with single layer $\gamma$-alumina membranes (codes Al1-Si1-..). Some membranes have been modified a second time after separation experiments. Results after the first modification step are referred to as....-(1), while the code for the measurements after the second modification step is....-(2).

The most direct observation is that the separation factors are much higher than might be expected based on separation according to Knudsen diffusion. Maximum separation factors can then be found by taking the inverse square root of the ratio of the molecular 
Table 5

Apparent activation energies of permeation for silica modified membranes Al3-Sil- with different $\mathrm{H}_{2}$ activation energy

\begin{tabular}{|c|c|c|c|c|c|c|}
\hline & \multicolumn{6}{|c|}{$E_{\mathrm{act}}^{\mathrm{a}} \mathrm{kJ} / \mathrm{mol}$} \\
\hline & $\mathrm{He}$ & $\mathrm{H}_{2}$ & $\mathrm{CO}_{2}$ & $\mathrm{O}_{2}$ & $\mathbf{N}_{2}$ & $\mathrm{CH}_{4}$ \\
\hline \multicolumn{7}{|c|}{ Membrane: } \\
\hline B & - & 14.921 .7 & 6.114 .9 & - & - & - \\
\hline $\mathrm{C}$ & - & 13.216 .9 & 5.611 .3 & - & - & - \\
\hline SiTi-Pr ${ }^{b}$ & - & 12.316 .3 & 2.63 .9 & - & - & - \\
\hline $\mathrm{D}^{\mathrm{b}}$ & - & 11.012 .3 & 2.02 .7 & - & - & - \\
\hline $\mathrm{SiAl}^{\mathrm{b}}$ & - & 9.09 .2 & 6.06 .5 & - & - & - \\
\hline $\mathbf{E}$ & - & 8.011 .2 & 0.94 .8 & 1519.5 & - & - \\
\hline $\mathbf{U} 1^{d}$ & 1.74 .0 & 7.410 .0 & c & - & - & - \\
\hline SiTi-Bu ${ }^{b}$ & - & 7.08 .4 & 1.41 .7 & - & - & - \\
\hline $\mathbf{U} 2^{\mathrm{d}}$ & 4.79 .0 & 6.711 .0 & 6.710 .0 & - & - & - \\
\hline$F$ & - & 5.88 .3 & - & 2.23 .0 & 7.59 .0 & - \\
\hline$A^{e}$ & - & 5.411 .0 & c & $c$ & - & 6.77 .9 \\
\hline $\mathrm{A}$ & - & 5.07 .4 & c & 7.08 .4 & 5.05 .5 & 1.71 .8 \\
\hline$G$ & - & 4.45 .8 & - & - & - & - \\
\hline $\mathrm{H}$ & - & 3.26 .6 & c & - & - & - \\
\hline
\end{tabular}

${ }^{a}$ Italic values corrected for support influence.

${ }^{c}$ Decreasing permeation as function of temperature.

${ }^{\mathrm{d} D a t a}$ taken from Uhlhorn [14].

bData taken from [17].

eSingle layer $\gamma$-alumina.

masses, resulting in $\alpha_{\mathrm{Knudsen}, \mathrm{H} 2 / \mathrm{CH}_{4}}=2.82$ and $\alpha_{\mathrm{Knudsen}}$ $\mathrm{H}_{2} /$ isobutane $=5.39$. Further it can be observed that the separation factor for $\mathrm{H}_{2}$ versus other molecules increases as the difference in molecular size is larger; $\alpha_{\mathrm{H} 2 / \text { iso-C4H10 }} \gg \alpha_{\mathrm{H} 2 / \mathrm{CH} 4}$ and $\alpha_{\mathrm{H} 2 / \mathrm{CH} 4}>\alpha_{\mathrm{H} 2 / \mathrm{CO} 2}$. This effect is more pronounced at higher temperatures.

In general, the $\mathrm{H}_{2} /-$ separation factors increase with temperature. In some cases, however, a maximum or a decrease in separation factor for $\mathrm{H}_{2} / \mathrm{CH}_{4}$ as function of temperature is observed. This can be explained by the support influence. At higher temperatures, the relative pressure drop over the support increases, due to the increased permeation for the top-layer and the decreased permeation of the support. The support resistance can then increase to about $40 \%$ of the total resistance. At a certain point, which is at lower temperatures for low quality membranes (where the contribution of transport through cracks and pinholes is high), transport through the support is rate determining. The separation factor will therefore decrease.
The improvement of the $\mathrm{H}_{2} / \mathrm{CH}_{4}$ selectivity due to the second modification for membrane Al1-Si2-A is about a factor 2. Membrane Al3-Si2-A, however, has shown a significantly larger improvement of the $\mathrm{H}_{2}$ / $\mathrm{CH}_{4}$ separation factor at $300^{\circ} \mathrm{C}$ from 11 to 40 [17]. This difference may be related with the fact that membrane surfaces are damaged by removing them from the permeation cell. Because the membranes are sealed on the top-layer with O-rings, the top-layer surface will be damaged at the place where it is in contact with the sealing. This damage varies from case to case and may cause some additional leaking when the sealing in the experiments after the second modification does not cover these damaged spots.

The fact that the $\mathrm{H}_{2}$ /isobutane separation factor is already high after the first modification step for membrane Al1-Sil-A leads to the conclusion that the defects which result in the low separation factor for $\mathrm{H}_{2} /$ $\mathrm{CH}_{4}$ are very small. They are certainly not large cracks or pinholes. 
Table 6

Separation factors for silica modified membranes

Membrane System $\alpha$

$22^{\circ} \mathrm{C} \quad 50^{\circ} \mathrm{C} \quad 100^{\circ} \mathrm{C} \quad 150^{\circ} \mathrm{C} 200^{\circ} \mathrm{C} 250^{\circ} \mathrm{C}$

\begin{tabular}{|c|c|c|c|c|c|c|c|}
\hline $\begin{array}{l}\text { Al3-Si1- } \\
\mathrm{Ul}^{\mathrm{a}}\end{array}$ & $\begin{array}{l}\mathrm{H}_{2} / \\
\mathrm{C}_{3} \mathrm{H}_{6}\end{array}$ & 13.4 & - & 62 & - & 156 & $>272^{b}$ \\
\hline $\begin{array}{l}\text { Al3-Sil- } \\
\mathrm{U2}^{\mathrm{a}}\end{array}$ & $\begin{array}{l}\mathrm{CO}_{2} / \\
\mathrm{CH}_{4}\end{array}$ & 48 & - & 65 & - & 28 & - \\
\hline $\begin{array}{l}\mathrm{Al} 3-\mathrm{Si} 2-\mathrm{A}- \\
\text { (1) }\end{array}$ & $\mathrm{H}_{2} / \mathrm{CO}_{2}$ & 1.7 & - & 2.5 & 4.5 & 5.5 & 6.6 \\
\hline $\begin{array}{l}\mathrm{Al} 3-\mathrm{Si} 2-\mathrm{A}- \\
\text { (1) }\end{array}$ & $\mathrm{H}_{2} / \mathrm{CH}_{4}$ & 2 & 3 & 5 & 8 & 11 & 12 \\
\hline $\begin{array}{l}\text { Al3-Si2-A- } \\
\text { (2) }\end{array}$ & $\mathrm{H}_{2} / \mathrm{CH}_{4}$ & 2 & 3 & 5 & 10 & i8 & 30 \\
\hline $\mathrm{Al} 3-\mathrm{SiTi}^{\mathrm{c}}$ & $\mathrm{H}_{2} / \mathrm{CH}_{4}$ & 12 & 50 & 150 & 200 & 165 & - \\
\hline Al3-Sil-K & $\mathrm{H}_{2} / \mathrm{CH}_{4}$ & 6.3 & - & 17.2 & - & - & - \\
\hline Al3-Si1-L & $\mathrm{H}_{2} / \mathrm{CH}_{4}$ & 10 & 35 & - & - & - & - \\
\hline All-Si1-B & $\mathrm{H}_{2} / \mathrm{CH}_{4}$ & - & 5.5 & 5.7 & 5.7 & 5.7 & 5.5 \\
\hline All-Si1-B & $\mathrm{H}_{2} /$ i.b. & - & 80 & 105 & 110 & 110 & 110 \\
\hline $\begin{array}{l}\text { All-Si2-A- } \\
\text { (1) }\end{array}$ & $\mathrm{H}_{2} / \mathrm{CH}_{4}$ & - & 6.5 & 6.2 & 6 & 6 & 5.8 \\
\hline $\begin{array}{l}\text { All-Si2-A- } \\
\text { (1) }\end{array}$ & $\mathrm{H}_{2} /$ i.b. & - & 130 & 150 & 150 & 180 & - \\
\hline $\begin{array}{l}\mathrm{Al1}-\mathrm{Si} 2- \\
\mathrm{A}-(2)\end{array}$ & $\mathrm{H}_{2} / \mathrm{CH}_{4}$ & - & 9.8 & 10.2 & 10.5 & 10.5 & 10.5 \\
\hline $\begin{array}{l}\mathrm{All}-\mathrm{Si} 2- \\
\mathrm{A}-(2)\end{array}$ & $\mathrm{H}_{2} /$ i.b. & - & 80 & 130 & 170 & 180 & $170^{d}$ \\
\hline
\end{tabular}

${ }^{\mathrm{a} D a t a}$ taken from Uhlhorn [14].

${ }^{\mathrm{b}} \mathrm{T}=260^{\circ} \mathrm{C}$.

'Data taken from [17]

${ }^{\mathrm{d}} \mathrm{T}=300^{\circ} \mathrm{C}$.

\section{Analysis of the gas transport mechanism: integration of sorption and permeation data}

\subsection{Analysis of interface processes; gas phase diffusion and external adsorption}

Based on the summary of permeation results (Tables 4 and 5), and the measured isosteric heats of adsorption (Table 2), an analysis of the influence of interface processes on the permeation mechanism can be made. In first instance we will use Eq. (13), according to the analysis of Barrer [37], for the assessment of the influences of surface processes on micropore diffusion.

A worst case assessment can be made by setting both $\theta_{1, \mathrm{eq}} \rightarrow 0$ and $\theta_{n, \mathrm{eq}} \rightarrow 0$. The analysis will be performed for $\mathrm{H}_{2}$ and $\mathrm{CO}_{2}$, since for these gases the most reliable permeation data are obtained, and because of the strong difference in adsorption characteristics for these gases.
If the membrane thickness ( $l$ ) and the mean jump distance $(d)$ are approximated by $100 \mathrm{~nm}$ and $5 \times 10^{-10} \mathrm{~m}$ respectively, Eq. (13) turns to:

$\frac{J_{\text {id }}}{J}=1+10^{-2} \exp \left(\frac{\delta \Delta E}{R T}\right)$

with $\delta \Delta E=\left(E_{\mathrm{s}}+\Delta E-\Delta E_{\mathrm{s}}-E_{1}\right) . \quad J_{\mathrm{id}} / J$ then expresses the deviation of transport from ideal micropore diffusion.

The values for $q^{\text {st }}$ for $\mathrm{H}_{2}$ and $\mathrm{CO}_{2}$ are $6.1 \mathrm{~kJ}$.mol ${ }^{-1}$ and $22.3 \mathrm{~kJ} . \mathrm{mol}^{-1}$ respectively, and are equal to $-\Delta E$, the energy difference between molecules in the gas phase and in the micropores [37]. From Table 5 it follows that for good quality membranes, the corrected apparent activation energies for $\mathrm{H}_{2}$ and $\mathrm{CO}_{2}$ are approximately $15 \mathrm{~kJ} \cdot \mathrm{mol}^{-1}$ and $10 \mathrm{~kJ} \cdot \mathrm{mol}^{-1}$. The value of the activation energy $E_{1}$ for the intra-crystalline diffusion is then assessed by (19), where interface processes are neglected in a first approximation. The resulting calculated values for the activation energy of the intracrystalline micropore diffusion $\left(E_{1}\right)$ are around 21 $\mathrm{kJ} . \mathrm{mol}^{-1}$ for $\mathrm{H}_{2}$ and $32 \mathrm{~kJ} \cdot \mathrm{mol}^{-1}$ for $\mathrm{CO}_{2}$.

In Table 7 the results of some calculations are given for the assessment of $J_{\text {id }} / J$. Initially, no surface barriers for $\mathrm{H}_{2}\left(\Delta E_{\mathrm{s}}\right.$ and $E_{\mathrm{s}}$, see Fig. 2) are taken into account, which implies that $\delta \Delta E=\Delta E-E_{1}$. This situation cor-

Table 7

Analysis of influence of interface processes on micropore diffusion

\begin{tabular}{lllllll}
\hline Gas & $\Delta E-E_{1}$ & $\Delta E_{\mathrm{s}}$ & $E_{\mathrm{s}}$ & $\delta \Delta E$ & $T(\mathrm{~K})$ & $J_{\mathrm{id}} / J$ \\
\hline $\mathrm{H}_{2}$ & -15 & - & - & -15 & 300 & 1.000024 \\
& & & & & 600 & 1.0004 \\
$\mathrm{H}_{2}$ & & 6 & 10 & -11 & 300 & 1.00012 \\
& & & & & 600 & 1.0011 \\
$\mathrm{H}_{2}$ & & 3 & 6 & -12 & 300 & 1.00008 \\
& & & & & 600 & 1.0009 \\
$\mathrm{H}_{2}$ & & 3 & 20 & 2 & 300 & 1.022 \\
& & & & & 600 & 1.015 \\
$\mathrm{CO}_{2}$ & -10 & - & - & -10 & 300 & 1.00018 \\
& & & & & 600 & 1.0013 \\
$\mathrm{CO}_{2}$ & 20 & 20 & -10 & 300 & 1.00018 \\
& & & & & 600 & 1.0013 \\
$\mathrm{CO}_{2}$ & 10 & 20 & 0 & 300 & 1.01 \\
& & & & & 600 & 1.01 \\
$\mathrm{CO}_{2}$ & 10 & 25 & 5 & 300 & 1.074 \\
& & 20 & 35 & & 600 & 1.028 \\
$\mathrm{CO}_{2}$ & 10 & 35 & 15 & 300 & 5.1 \\
& & & & & 600 & 1.2 \\
\hline
\end{tabular}

Energies in units of $\mathrm{kJ} \cdot \mathrm{mol}^{-1}$. 
responds to Fig. 1, by neglecting F2.J (which is the fraction of the flux via the external surface), and to Fig. 2 (b). The deviation from ideality $\left(J_{\mathrm{id}} / J=1\right)$ is then only 0.04 percent at $600 \mathrm{~K}$.

When fraction F2.J has to be analyzed, the problem arises that the heights of the surface barriers $\Delta E_{\mathrm{s}}$ and $E_{\mathrm{s}}$ (see Fig. 2(a)) are not known; $\Delta E_{\mathrm{s}}$, however, can not be higher than $\Delta E$. Therefore three fictive combinations are given, with $\Delta E_{\mathrm{s}}=6 \mathrm{~kJ} \cdot \mathrm{mol}^{-1}(\approx \Delta E)$ and $\Delta E_{\mathrm{s}}=3 \mathrm{~kJ} . \mathrm{mol}^{-1}(\approx 0.5 \times \Delta E)$. These combinations do not all result in significant deviations from ideality. The maximum deviation is found when a very high surface barrier $E_{\mathrm{s}}$ is chosen of $20 \mathrm{~kJ} . \mathrm{mol}^{-1}$, which is of the same order as the activation energy for micropore diffusion $E_{1}$. The deviation is then only $2 \%$ at $300 \mathrm{~K}$. The calculation of $E_{1}$ for hydrogen from the preceding procedure therefore seems justified.

For $\mathrm{CO}_{2}$ the deviation from ideality in the absence of additional surface barriers is slightly higher, as might expected from the stronger sorption, but is still very small. The introduction of surface barriers lower than the assessed intra-crystalline diffusion coefficient of 32 $\mathrm{kJ} . \mathrm{mol}^{-1}$, also did not lead to significant deviations from ideality. Only a very high value for $E_{\mathrm{s}}$ of 35 $\mathrm{kJ} . \mathrm{mol}^{-1}$, leading to $E_{\mathrm{s}}-\Delta E_{\mathrm{s}}=25 \mathrm{~kJ} \cdot \mathrm{mol}^{-1}$, results in a strong influence of surface processes, at low temperatures. However, in this latter case the followed procedure to calculate $E_{1}$ is not valid any more. Surface transport is therefore not rate determining in the situations studied $\left(28^{\circ} \mathrm{C}<T<300^{\circ} \mathrm{C}, 0<P<4\right.$ bar $)$.

This is supported by the temperature dependency of surface diffusion as discussed before (Eq. (4)). The total transport rate $\left(\mathrm{mol} . \mathrm{s}^{-1} \cdot \mathrm{m}^{-1}\right)$ always decreases as the temperature is increased. External surface diffusion can therefore not be rate determining if activated transport is found for the actual situation.

Also gas transport from the gas phase to the membrane is not likely to be rate determining as can be analyzed by kinetic gas theory [43]. The total number of molecules colliding with the wall of a volume, $Z_{\text {wall }}\left(\mathrm{s}^{-1} . \mathrm{cm}^{-2}\right)$, can be expressed by:

$Z_{\text {wall }}=\frac{1}{4} \frac{N}{V} \bar{v}$

where $N / V$ is the number of molecules per unit of volume $\left(\mathrm{cm}^{-3}\right)$, and $\bar{v}$ is molecular velocity $\left(\mathrm{cm} \cdot \mathrm{s}^{-1}\right)$.

It follows that the molar flux colliding with the wall for hydrogen is around $1.8 \mathrm{~mol} . \mathrm{cm}^{-2} . \mathrm{s}^{-1}$ at $300 \mathrm{~K}$ and
$1 \mathrm{~atm}$. pressure. A typical hydrogen flux through the microporous membranes is around $10 \times 10^{-6}$ mol.cm ${ }^{-2} . \mathrm{s}^{-1}$ (calculated from a permeation value of $10 \times 10^{-7} \mathrm{~mol} \cdot \mathrm{m}^{-2} \cdot \mathrm{s}^{-1} \cdot \mathrm{Pa}^{-1}$ at $1 \mathrm{~atm}$.). Even with a porosity of $1 \%$ and a sticking probability of $1 \%$, which is a pessimistic assessment, the collisional flux is more than one order of magnitude higher than the permeation.

\subsection{Delineation of the Henry region}

The preceding analysis of external interface processes is only valid when sorption behavior follows Henry's Law. If this is not the case, the elimination of interface processes to analyse micropore diffusion will be very difficult [37]. As shown by the sorption data, Henry's Law is followed below $125 \mathrm{kPa}$ for $\mathrm{H}_{2}$ at temperatures equal and higher than $194 \mathrm{~K}$, for $\mathrm{CH}_{4}$ at temperatures equal and higher than $273 \mathrm{~K}$, for $\mathrm{CO}_{2}$ at temperatures equal and higher than $348 \mathrm{~K}$, and for isobutane at temperatures higher than $373 \mathrm{~K}$. Henry behavior up to more than 15 bar was observed for $\mathrm{CO}_{2}$ at $373 \mathrm{~K}$. Due to the considerably lower sorption capacity and isosteric heat of adsorption for $\mathrm{H}_{2}$ and $\mathrm{CH}_{4}$ compared to $\mathrm{CO}_{2}$, it can be assumed safely that for these gases Henry's Law will be followed at high temperatures $(T>373 \mathrm{~K})$ and pressures up to at least 15 bar as well.

At a lower temperature of $273 \mathrm{~K}$, strong non-Henry behavior is observed for $\mathrm{CO}_{2}$ (below 5 bar) and isobutane (below 1 bar) [32]. The minimum temperature used for the permeation and separation measurements in this work is $25^{\circ} \mathrm{C}$. In the case of $\mathrm{CO}_{2}$, no significant deviation from Henry's Law takes place at this temperature, which explains the perfect pressure independent permeation up to 5 bar as presented in Fig. 7. This is in agreement with the description of the permeation according to Eq. (18), which assumes Henry sorption.

The effect of introducing non-Henry conditions in permeation through microporous membranes has been shown by Bakker and Geus [28,29] for MFI membranes. They report that methane/n-butane separation experiments show that the system is selective for $n$ butane at low temperatures giving rise to a selectivity of 53 at $300 \mathrm{~K}$ using a $50 / 50$ feed composition. It is concluded that the high selectivity towards n-butane is due to the fact that at low temperatures n-butane adsorbs strongly, and therefore hinders methane per- 
Table 8

Calculated diffusion coefficients at $298 \mathrm{~K}$

\begin{tabular}{llcll}
\hline Membrane & $\mathrm{Gas}$ & $J(298 \mathrm{~K})\left(\mathrm{mol} . \mathrm{m}^{-2} \cdot \mathrm{s}^{-1}\right)$ & $K(298 \mathrm{~K})\left(\mathrm{mol}^{\mathrm{kg}} \mathrm{kg}^{-1} \cdot \mathrm{Pa}^{-1}\right)$ & $D(298 \mathrm{~K})\left(\mathrm{m}^{2} . \mathrm{s}^{-1}\right)$ \\
\hline \multirow{2}{*}{ Al3-Sil-A } & $\mathrm{H}_{2}$ & $6.8 \times 10^{-2}$ & $1.44 \times 10^{-7}$ & $1.43 \times 10^{-10}$ \\
& $\mathrm{CO}_{2}$ & $3.6 \times 10^{-2}$ & $1.42 \times 10^{-5}$ & $7.68 \times 10^{-13}$ \\
\multirow{4}{*}{ Al3-Si1-B } & $\mathrm{CH}_{4}$ & $0.27 \times 10^{-2}$ & $1.57 \times 10^{-6}$ & $5.2 \times 10^{-13}$ \\
& $\mathrm{H}_{2}$ & $2.28 \times 10^{-2}$ & $1.44 \times 10^{-7}$ & $4.8 \times 10^{-11}$ \\
All-Sil-A & $\mathrm{CO}_{2}$ & $3.0 \times 10^{-2}$ & $1.42 \times 10^{-5}$ & $6.4 \times 10^{-13}$ \\
& $\mathrm{H}_{2}$ & $12 \times 10^{-2}$ & $1.44 \times 10^{-7}$ & $2.5 \times 10^{-10}$ \\
& $\mathrm{CO}_{2}$ & $4.2 \times 10^{-2}$ & $1.42 \times 10^{-5}$ & $9.0 \times 10^{-13}$ \\
& $\mathrm{CH}_{4}$ & $0.78 \times 10^{-2}$ & $1.57 \times 10^{-6}$ & $1.5 \times 10^{-12}$ \\
& $\mathrm{i}-\mathrm{C}_{4} \mathrm{H}_{10}$ & $0.8 \times 10^{-2}$ & $7.30 \times 10^{-5}$ & $3.3 \times 10^{-14}$ \\
\hline
\end{tabular}

meation. At higher temperatures, however, n-butane desorbs and follows Henry' Law. This results in an increased methane permeation. At $623 \mathrm{~K}$ the membrane is then selective for methane; the separation factor is 0.6 . In this case the fluxes reflect the pure gas permeation rates.

\subsection{Estimation of $D$ and $E_{I}$}

Since Henry sorption has been proven for the experimental conditions in our study, Eq. (18) can be used to describe gas transport in these microporous membranes. The membrane thickness is $100 \mathrm{~nm}$, the skeletal density is $2.2 \mathrm{~kg} \cdot \mathrm{m}^{-3}$, the porosity is 0.4 , the pressure difference is taken to be $1 \mathrm{bar}$, and the values for $K$ are calculated from Table 2. By substitution of these parameters in Eq. (18), the diffusion coefficients $D$ $\left(\mathrm{m}^{2} . \mathrm{s}^{-1}\right)$ at $298 \mathrm{~K}$ can now be calculated according to Eq. (26):

$J=3.3 \times 10^{15} D_{(298 K)} K_{(298 K)}$

Some results from these calculations are given in Table 8 . The calculations are performed for membranes Al3-Sil-A $\left(E_{\text {act, } \mathrm{H} 2}=7.4 \mathrm{~kJ} \cdot \mathrm{mol}^{-1}\right.$ (corrected)), Al3Sil-B $\left(E_{\text {act, } \mathbf{H} 2}=21.7 \mathrm{~kJ} \cdot \mathrm{mol}^{-1}\right.$ (corrected) $)$ and Al1Sil-A $\left(E_{\text {act }, \mathrm{H} 2}=11.0 \mathrm{~kJ} \cdot \mathrm{mol}^{-1}\right.$ (corrected) $)$. The flux values are calculated from the corrected permeation rates. The order of the calculated diffusion coefficients is comparable with literature results for diffusion in zeolites [44]. One should bear in mind, however, that the calculation is very sensitive to the values used, and the porosity of the supported membranes is still questionable. Comparison of diffusion coefficients from the literature must therefore be performed carefully.
It can be seen that the diffusion coefficient for hydrogen is about two orders of magnitude higher than for methane and carbon dioxide, and four orders of magnitude higher than for iso-butane. These differences are much more pronounced than the differences in membrane permeation, and indicate directly the impact of the sorption characteristics of the gases used. Since the difference in kinetic diameter between hydrogen and methane is small $(0.289$ and $0.38 \mathrm{~nm}$, respectively), the large difference in diffusion coefficient suggests large differences in resistance for transport in the pore. Consequently, the pore constrictions must be of molecular size.

\subsection{Evaluation}

Evaluation of activation energies in zeolites [45] shows that there is a relation between the relative pore size of gas molecules in the pores and the activation energy for diffusion. Generally, the activation energy is lower for larger pores than for small pores, and the activation energy in a certain zeolite increases as the size of the molecule is increased [44]. Comparison of the calculated activation energy for intracrystalline diffusion for $\mathrm{H}_{2}$ and $\mathrm{CO}_{2}$ of $21.1 \mathrm{~kJ} \cdot \mathrm{mol}^{-1}(5.0$ kcal.mol $\left.{ }^{-1}\right)$ and $32.3 \mathrm{~kJ} . \mathrm{mol}^{-1}\left(7.7 \mathrm{kcal} . \mathrm{mol}^{-1}\right)$ respectively shows that the experimentally found activation energy values for $\mathrm{CO}_{2}$ are higher than for e.g. $\mathrm{CO}_{2}, \mathrm{CH}_{4}$ and $\mathrm{C}_{2} \mathrm{H}_{6}$ in zeolite $4 \mathrm{~A}$ (pore diameter 0.4 $\mathrm{nm}$ ). The activation energy found for hydrogen is of the same order of activation energies found for $\mathrm{Ar}, \mathrm{Kr}$, $\mathrm{O}_{2}, \mathrm{~N}_{2}$ and $\mathrm{CH}_{4}$ [46]. Based on this, it can be concluded that the pore constrictions of our membranes are smaller than $0.4 \mathrm{~nm}$. It has to be noted, however, that in general the variation in calculated activation energies 
for gas transport through zeolites is quite large, and that direct comparison is difficult [33]. This indicates indeed that the pore size calculated by $\mathrm{N}_{2}$-adsorption on non-supported membranes $(0.5-0.75 \mathrm{~nm})$ may give an overestimate.

This conclusion is supported by the comparison of the separation properties with results obtained with zeolite membranes. Silicalite $\left(d_{\text {pore }} \approx 5.5 \AA\right)$ membranes prepared by Geus and Bakker et al. [28,29] show no activated transport for hydrogen and only a maximum permselectivity for $\mathrm{H}_{2} / \mathrm{CH}_{4}$ of 15.5 at $21^{\circ} \mathrm{C}$. The absence of activated transport for these membranes, contrary to the microporous sol-gel derived membranes, may be a second indication that the pore size of the supported microporous sol-gel derived membranes is probably smaller than the ones determined from $\mathrm{N}_{2}$-adsorption measurements on non-supported membranes.

However, these conclusions seems to contradict the conclusion from the sorption study [20,32]. Based on the lower isosteric heat of adsorption of the sol-gel derived non-supported silica compared with zeolite data, it was concluded that the pore size is probably larger than for zeolites $3 \mathrm{~A}, 5 \mathrm{~A}$ or silicalite. It should be remembered, as discussed before [17,19], that comparison of the microstructure of the non-supported materials and supported materials is difficult. Since the layer thickness is greater for non-supported membranes, this leads to longer drying times. Further condensation of the polymeric sol can then take place leading to a stronger gel. Consequently, this gel may be more open. An opposing effect, however, is that support constraints will hinder densification of supported membranes. Based on these results, the influence of the relatively high consolidation rate on the formed microstructure probably prevails for the supported membranes, and support constraints are less important, which can be explained by the high flexibility of the sol polymers.

For non-supported membranes it was found [42] that the prepared microporous materials have a bimodal pore size distribution with maxima at effective pore diameters of around 0.5 and $0.75 \mathrm{~nm}$. This corresponds to physical pore diameters (defined as the distance between surface oxygen nuclei, with $d_{\text {surface, oxygen }}$ ion $=0.276 \mathrm{~nm}$ ) of respectively $0.776 \mathrm{~nm}$ and 1.026 $\mathrm{nm}$. The relative pore size $R / \sigma$ for hydrogen $\left(\sigma_{\mathrm{H} 2}=0.289 \mathrm{~nm}\right)$ is then 1.34 and 1.78 , respectively.
In the analysis of the surface potentials in micropores, as given by Everett and Powl [38] and presented in Fig. $3, R / \sigma=1.34$ refers to the situation where the potential enhancement at the local maximum is around a factor 2, and in the local minimum a factor 2.5. At $R / \sigma=1.78$, the enhancement in the local maximum is about a factor 1 , and in the local minimum about a factor 1.8. This implies that molecules always move through an enhanced potential field.

When the pores are indeed as small as indicated before $\left(d_{\text {pore }} \approx 0.4 \mathrm{~nm}\right), R / \sigma=0.75$. This corresponds to situation a in Fig. 3 that the pore is already so small that the potential has passed the minimum, and is becoming less positive. Another consequence is that $\mathrm{H}_{2}$ and $\mathrm{CH}_{4}$, with kinetic diameters $\sigma$ of respectively $0.289 \mathrm{~nm}$ and $0.38 \mathrm{~nm}$, cannot pass each other in the case that the pores are ideally cylindrical. True molecular sieving (size exclusion) should then take place. Small variations in pore size should than have quite a large effect, as is experimentally shown by comparison of $\mathrm{H}_{2} / \mathrm{CH}_{4}$ and $\mathrm{H}_{2} /$ isobutane separation experiments.

Since the porous structure is formed from very flexible, weakly branched polymers, it is not likely that ideally cylindrical pores are formed, but very probably an interconnected network of pores. In this case, and unless the concentration in the pores is very high, which means that sorption takes place outside the Henry region, molecules can pass each other by moving through the whole network.

Extrapolations of permeation data to higher pressures for the assessment of permeation rates are most probably allowed since Henry's law is followed up to high pressures, in the order of $15 \mathrm{bar}$, when the temperature is higher than around $100^{\circ} \mathrm{C}$. For $\mathrm{H}_{2}$ at $200^{\circ} \mathrm{C}$, for example, the permeation rate is in the order of $20 \times 10^{-7} \mathrm{~mol} \cdot \mathrm{m}^{-2} \cdot \mathrm{s}^{-1} \cdot \mathrm{Pa}^{-1}$, which corresponds to around $400 \mathrm{~m}^{3} \cdot \mathrm{m}^{-2}$.day ${ }^{-1} \cdot$ bar $^{-1}$.

At a feed pressure and pressure difference of 15 bar, this results in a membrane flux of $6000 \mathrm{~m}^{3} \cdot \mathrm{m}^{-2}$.day ${ }^{-1}$, which is of a commercially very interesting order.

\section{Conclusions}

Gas transport through the sol-gel derived microporous membranes is activated and shows molecularsieve-like separation properties with relatively high permeation rates. Typical apparent activation energies 
for permeation, after correction for support influence, for $\mathrm{H}_{2}$ and $\mathrm{CO}_{2}$ are 17-22 kJ.mol ${ }^{-1}$ and 10-15 $\mathrm{kJ} . \mathrm{mol}^{-1}$, respectively, for high quality membranes. Permeation rates for hydrogen at $200^{\circ} \mathrm{C}$ are typically $20 \times 10^{-7} \mathrm{~mol} \cdot \mathrm{m}^{-2} \cdot \mathrm{s}^{-1} \cdot \mathrm{Pa}^{-1}$ and $5 \times 10^{-7}$ mol.m ${ }^{-2} \cdot \mathrm{s}^{-1} \cdot \mathrm{Pa}^{-1}$ for $\mathrm{CO}_{2}$.

Separation factors are in the order of 20-30 for $\mathrm{H}_{2} /$ $\mathrm{CH}_{4}$ and $150-200$ for $\mathrm{H}_{2} /$ isobutane at $200-300^{\circ} \mathrm{C}$ for high quality membranes.

It is shown that interface processes are not rate determining for the conditions studied. The activation energy for micropore diffusion can therefore be calculated from the apparent activation energy for permeation and the isosteric heat of adsorption. The calculated activation energies for $\mathrm{H}_{2}$ and $\mathrm{CO}_{2}$ micropore diffusion are around $21 \mathrm{~kJ} \cdot \mathrm{mol}^{-1}$ and 32 kJ.mol ${ }^{-1}$.

When strong non-Henry sorption takes place, the separation mechanism is expected to show an inverse behavior, since the stronger adsorbing molecules will block the pores and hinder the weakly sorbing gas.

From comparison of the calculated activation energy for micropore diffusion with zeolite diffusion data, it is likely that the effective pore diameter for supported silica membranes is smaller than those calculated from experiments on non-supported membranes and is approximately $0.4 \mathrm{~nm}$.

Defects of moderate quality membranes result in separation factors of 5-10 for $\mathrm{H}_{2} / \mathrm{CH}_{4}$, but to high separation factors in the order of $100-120$ for $\mathrm{H}_{2}$ /isobutane at $200-300^{\circ} \mathrm{C}$. The defects are therefore very small and may be identical with some wider micropores.

The combination of high permeation rates and separation factors makes these membranes very attractive for gas separation applications and/or for membrane reactors. Even for moderate quality membranes, $\mathrm{H}_{2} /$ isobutane separations are of the order of 100-200. Estimated intrinsic fluxes (no substrate influence) for hydrogen at $200^{\circ} \mathrm{C}$, with a feed pressure and pressure difference of $15 \mathrm{bar}$, are in the order of 6000 $\mathrm{m}^{3} \cdot \mathrm{m}^{-2} \cdot \mathrm{day}^{-1}$.

\section{Acknowledgements}

J.H.A. Hekkink is thanked for performing many of the permeation measurements and Z.A.E.P. Vroon and V.T. Zaspalis for discussions related with the mecha- nism of gas transport in microporous materials. Special thanks to Prof. Y.H. Ma (Worcester Polytechnic Institute, Worcester MA, U.S.A) for his contribution on the sorption experiments. Shell Research B.V., Amsterdam is gratefully acknowledged for general financial support of the project.

\section{References}

[1] W.R. Gurr, An operators overview on gas membranes, in M.K. Turner (Editor), Effective Industrial Membrane Processes Benefits and Opportunities, Elsevier Science Publishers, Barking, UK, 1991, pp. 329-336.

[2] J. Gillot, The developing use of inorganic membranes: A historical perspective, in R.R. Bhave (Editor), Inorganic Membranes; Synthesis, Characteristics and Applications, Van Nostrand Reinhold, New York, 1991, pp. 1-9.

[3] K.S.W. Sing, D.H. Everett, R.A.W. Haul, L. Moscou, R.A. Pierotti, J. Rouquérol and T. Siemiewska, Reporting physisorption data for gas/solid systems with special reference to the determination of surface area and porosity, IUPAC Recommendations, 1984, Pure Appl. Chem., 57 (4) (1985) 603-619.

[4] R.R. Bhave, Inorganic Membranes: Synthesis, Characteristics and Applications, Van Nostrand Reinhold, New York, 1991.

[5] K. Keizer, R.J.R. Uhlhorn, V.T. Zaspalis and A.J. Burggraaf, Transport and related ( $g$ as and vapour) separation in ceramic membranes, Proc. Second Intern. Conf. Inorganic Membranes, Montpellier, 1991, Key Eng. Mater. 61/62 (1991) 143-154.

[6] A.J. Burggraaf, K. Keizer, R.S.A. de Lange, Z.A.E.P. Vroon and V.T. Zaspalis, Ceramic Membranes for separations and reactions, in J.B. Higgins, R. von Balmoos and M.M.J. Treacy (Editors), Proc. 9th Intern. Zeolite Conf., Montreal, Canada, July 5-10, 1992, Butterworth-Heinemann, Stoneham, MA, 1993, pp. 47-71.

[7] D.E. Fain, Technical and economic aspects and prospects for gas separation with inorganic membranes, Proc. Second Intern. Conf. Inorganic Membranes, Montpellier, 1991, Key Eng. Mater., $61 / 62$ (1991) 327-336.

[8] V.T. Zaspalis, K. Keizer, J.R.H. Ross and A.J. Burggraaf, Porous ceramic membranes in high temperature applications, Proc. Second Intern. Conf. Inorganic Membranes, Montpellier, 1991, Key Eng. Mater., 61/62 (1991) 359-364.

[9] V.T. Zaspalis, W. van Praag, K. Keizer, J.G. van Ommen, J.R.H. Ross and A.J. Burggraaf, Appl. Catal., 74 (1991) 205$222,223-234,235-248,249-260$.

[10] R.D. Noble and J.N. Armor, Special Issue on Membrane Catalysis, Appl. Catal. A: Gen., 69 (1993).

[11] J. Zaman and A. Chakma, Inorganic membrane reactors, J. Membrane Sci., 92 (1994) 1-28.

[12] V.T. Zaspalis, K. Keizer, A.J. Burggraaf and M.P. Harold, New Concepts in Reactor Applications; Membrane Reactors, Proc. Eur. Appl. Res. Conf. Natural Gas, Trondheim, Norway, June 1-3, 1992, pp. A143-A160. 
[13] K. Keizer, V.T. Zaspalis, R.S.A. de Lange, M.P. Harold and A.J. Burggraaf, Membrane reactors for partial oxidation and dehydrogenation reactions, in J. Crespo and K. Bödekker (Editor), Membrane Processes and Separation and Purification, Kluwer Academic Publishers, Dordrecht, The Netherlands, 1994, pp. 415-429.

[14] R.J.R. Uhlhorn, K. Keizer and A.J. Burggraaf, Gas transport and separation with ceramic membranes. Part II: Synthesis and separation properties of microporous membranes, J. Membrane Sci., $66(2 / 3)$ (1992) 271-288.

[15] S. Kitao, H. Kameda and M. Asaeda, Gas separation by thin porous silica membrane of ultra fine pores at high temperature, Membrane, 15 (4) (1990) 222-227.

[16] R.S.A. de Lange, J.H.A. Hekkink, K. Keizer and A.J. Burggraaf, Preparation and characterization of microporous sol-gel derived membranes for gas separation applications, in M.J. Hampden-Smith, W.G. Klemperer and C.J. Brinker (Editor), Better Ceramics through Chemistry V, Mat. Res. Symp. Proc., Vol. 271, Materials Research Society, Pittsburgh, 1992, pp. 505-510.

[17] R.S.A. de Lange, J.H.A. Hekkink, K. Keizer and A.J. Burggraaf, Formation and characterization of supported microporous ceramic membranes prepared by sol-gel modification techniques., J. Membrane Sci., accepted for publication.

[18] C.J. Brinker, T.L. Ward, R. Sehgal, N.K. Raman, S.L. Hietala, D.M. Smith, D.-W. Hua and T.J. Headley, Ultramicroporous silica-based supported inorganic membranes, J. Membrane Sci., 77 (1993) 165-179.

[19] R.S.A. de Lange, K-N.P. Kumar, J.H.A. Hekkink, G.M.H. van de Velde, K. Keizer, A.J. Burggraaf, W.H. Dokter, H.F. van Garderen and T.P.M. Beelen, Microporous $\mathrm{SiO}_{2}$ and $\mathrm{SiO}_{2} /$ $\mathrm{MO}_{\mathbf{x}}(\mathrm{M}=\mathrm{Ti}, \mathrm{Zr}, \mathrm{Al})$ for ceramic membrane applications; $\mathrm{A}$ microstructural study of the sol-stage and the consolidated state., J. Sol-Gel Sci. Technol., 2 (1994) 489-495.

[20] R.S.A. de Lange, Microporous sol-gel derived ceramic membranes for gas separation; Synthesis, gas transport and separation properties, PhD Thesis, University of Twente, Enschede, The Netherlands, 1993.

[21] R.S.A. de Lange, J.H.A. Hekkink, K. Keizer and A.J. Burggraaf, Permeation and separation studies on microporous sol-gel modified ceramic membranes, Microporous Mater., (1995) in press.

[22] T. Okubo and H. Inoue, Single gas permeation through porous glass modified with tetraethoxysilane, AIChE J., 35 (5) (1989) 845-848.

[23] G.R. Gavalas, C.E. Megiris and S.W. Nam, Deposition of $\mathrm{H}_{2}$ permselective $\mathrm{SiO}_{2}$ films, Chem. Eng. Sci., 44 (9) (1989) 1829-1835.

[24] S. Kitao and M. Asaeda, Gas separation performance of thin porous silica membranes prepared by sol-gel and CVDmethods, Key Eng. Mater., $61 / 62$ (1991) 267-272.

[25] Y.S. Lin and A.J. Burggraaf, Experimental studies on pore size changes of porous ceramic membranes after modification, $J$. Membrane Sci., 79 (1993) 65-82.
[26] A.B. Shelekhin, A.G. Dixon and Y.H. Ma, Adsorption, permeation, and diffusion of gases in microporous membranes. II. Permeation of gases in microporous glass membranes, $\mathrm{J}$. Membr. Sci., 75 (1992) 232-244.

[27] J. Koresh and A. Soffer, Study of molecular sieve carbon. Part 1. Pore structure, gradual pore opening and mechanism of molecular sieving, J. Chem. Soc. Faraday Trans., 76 (1980) 2457-2471.

[28] E.R. Geus, M.J. den Exter and H. van Bekkum, Synthesis and characterization of zeolite (MFI) membranes on porous ceramic supports, J. Chem. Soc. Faraday Trans., 88 (20) (1992) 3102-3109.

[29] W.J.W. Bakker, G. Zheng, F. Kapteijn, M. Makkee, J.A. Moulijn, E.R. Geus and H. van Bekkum, Single and multicomponent transport through metal-supported MFI zeolite membranes, in M.P.C. Weynen and A.A.H. Drinkenburg (Editors), Precision Process Technology; Perspectives for Pollution Prevention, Kluwer Academic Publishers, Dordrecht, The Netherlands, 1993, pp. 425-436.

[30] M.D. Jia, K.V. Peinemann and R.D. Behling, Ceramic zeolite composite membranes. Preparation, characterization and gas permeation, J. Membrane Sci., 82 ( 1993) 15-26.

[31] Z.A.E.P. Vroon, K. Keizer, H. Verwey and A.J. Burggraaf, Transport properties of a ceramic thin zeolite MFI membrane, Proc. Third Intern. Conf. Inorganic Membranes ICIM-3, July 1994, Worcester MA, USA, in press.

[32] R.S.A. de Lange, J.H.A. Hekkink, K. Keizer, A.J. Burggraaf and Y.H.Ma, Sorption studies of microporous sol-gel modified ceramic membranes, Microporous Mater., submitted 1994.

[33] J. Kärger and D.M. Ruthven, Diffusion in zeolites and other microporous materials, John Wiley and Sons, New York, 1992.

[34] M.F.M. Post, Diffusion in molecular sieves, in H. van Bekkum, E.M. Flanigen and J.C. Jansen (Editors), Introduction to Zeolite Science and Practice, Elsevier Science Publishers, Amsterdam, 1991, pp. 391-443.

[35] R.J.R. Uhlhorn and A.J. Burggraaf, Gas separations with inorganic membranes, in R.R. Bhave (Editor), Inorganic Membranes; Synthesis, Characteristics and Applications, Van Nostrand Reinhold, New York, 1991, pp. 155-176.

[36] E. Gilliland, R.F. Baddour and G.P. Perkinson, Diffusion on surfaces. Effect of concentration on the diffusivity of physically adsorbed gases, Ind. Eng. Fund., 13 ( 1974) 95-100.

[37] R.M. Barrer, Porous crystal membranes, J. Chem. Soc. Faraday Trans., 86 (7) (1990) 1123-1130.

[38] D.H. Everett and J.C Powl, Adsorption in slit-like and cylindrical micropores in the Henry's law region, J. Chem. Soc. Faraday Trans. I, 72 (1976) 619-636.

[39] D.W. Breck, Zeolite Molecular Sieves; Structure, Chemistry and Use, John Wiley and Sons, New York, 1973, p. 636.

[40] A. Saito and H.C. Foley, Curvature and parametric sensitivity in models of adsorption in micropores, AIChE J., 37 (3) (1991) 429-436.

[41] R.S.A. de Lange, K. Keizer and A.J. Burggraaf, Polymeric silica based sols for membrane modification applications: Solgel synthesis and characterization with SAXS, J. Non-Cryst. Solids, submitted 1994. 
[42] R.S.A. de Lange, K. Keizer and A.J. Burggraaf, Characterization of non-supported microporous membrane top-layers using physisorption techniques, J. Porous Mater., accepted for publication.

[43] P.C. Riedi, Thermal Physics, The MacMillan Press, London, 1976.
[44] See e.g. Ref. (34), pp. 418, 419, 422, 484

[45] Ref. (34), p. 419.

[46] Ref. (34), pp. 385-387. 